\title{
الآثار الاقتصادية للفساد الاقتصادي
}

أ. د. يحيى غني النجار

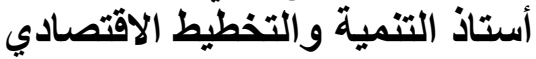

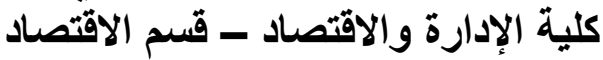

جامعة بغداد

\section{الخلاصة Abstract}

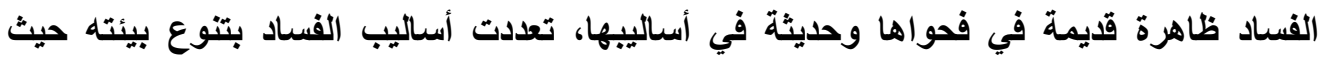

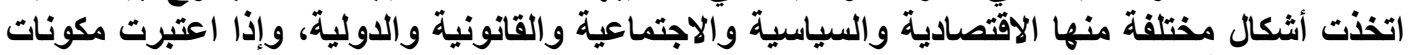

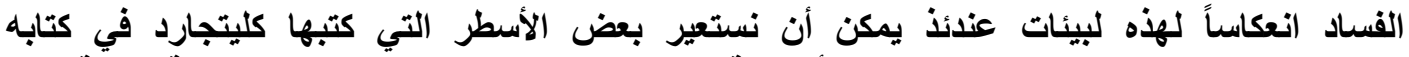

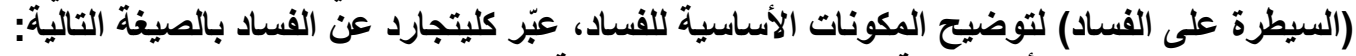

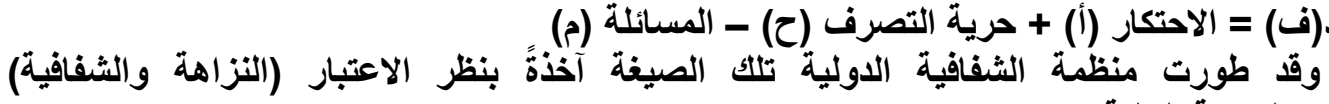

فوضعت الصيغة التالية :

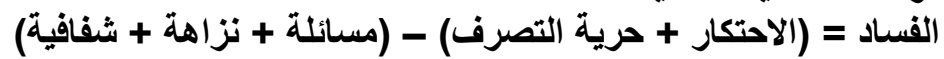

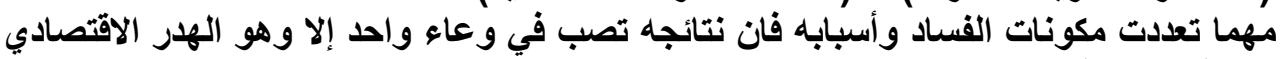

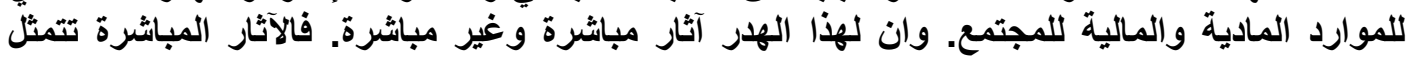

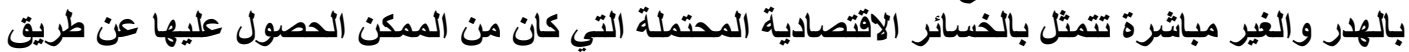

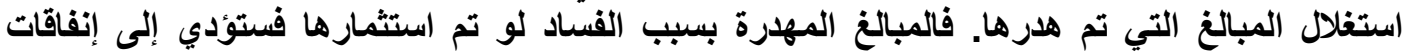

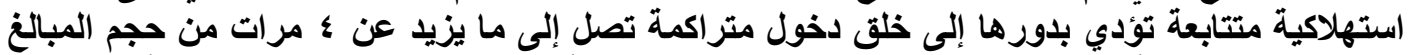

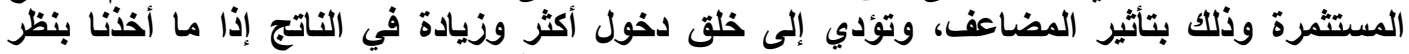

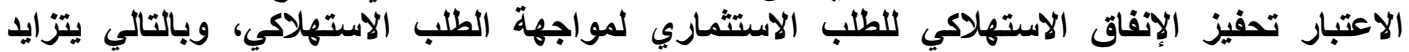

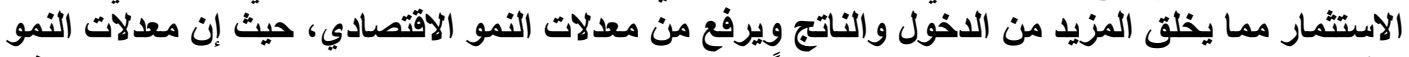

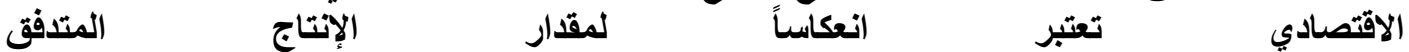

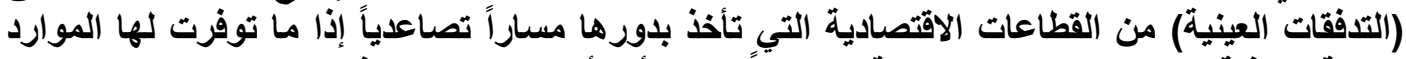

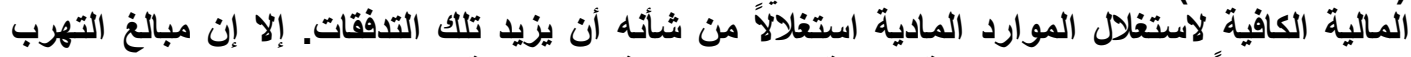

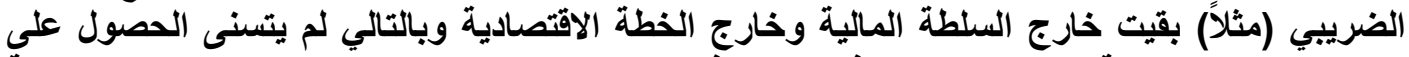

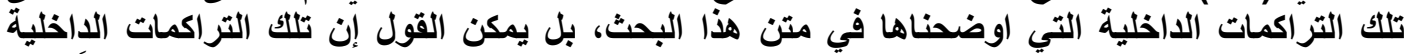

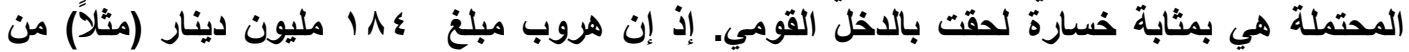

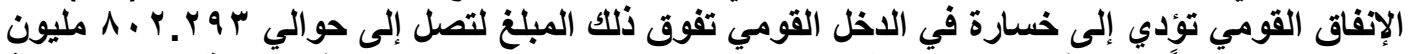

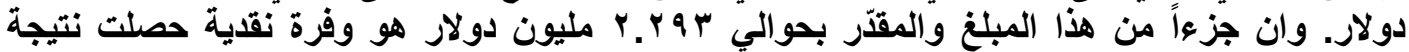

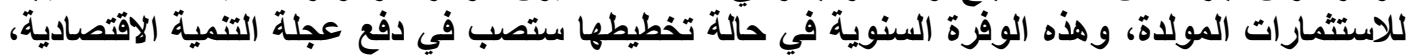

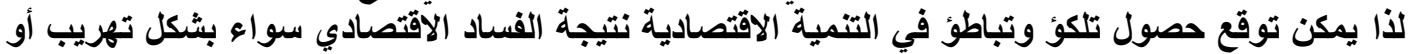

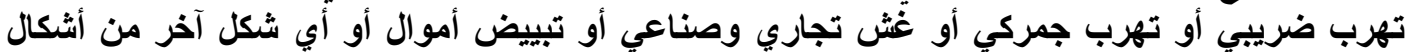




\section{Abstract}

There are many economic issues that concern society at the local and international levels and which constitute a serious challenge to the societies and governments, perhaps including the issue of corruption in all its forms and manifestations and effects, which now attract the attention the issue of human society everywhere .

The term "corruption" was not known in the literature or the media before the final quarter of last century, but spread widely and its negative made it impose itself strongly in global forums, and that started the last decade of the last century until the issue of corruption became the focus attention of researchers who studied forms of corruption.

Many of the studies discussed the issue of corruption has focused on non-economic reasons for corruption, and suggested means of reducing corruption through a package of laws and anti-corruption legislation and the application systems of good governance, either for reasons of economic corruption have been the lowest share of research and analysis. Despite the importance of non-economic causes of corruption, but the economic causes of great importance established by the facts in the form of slower economic growth and the erosion of available resources and deepening poverty situation, which requires due attention to this aspect. Thus, this research focus on the economic effects of corruption through disclosure of the nature of corruption and clarify concepts and factors of the spread and the impact on economics variables. 


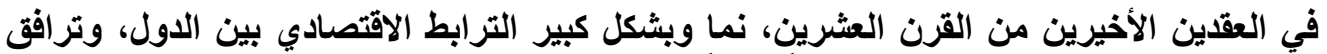

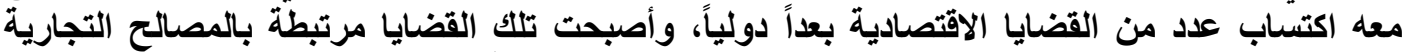

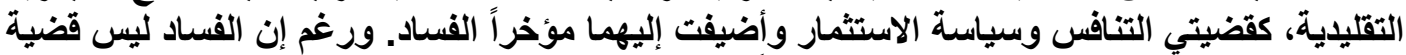

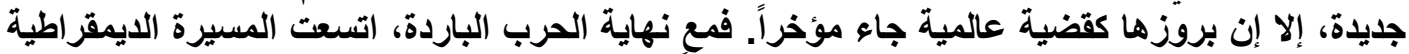

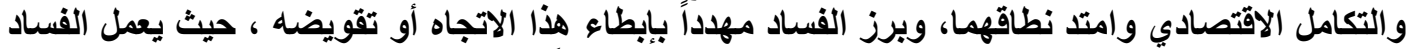

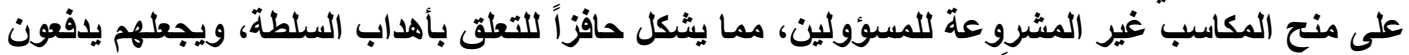

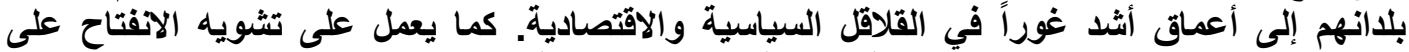

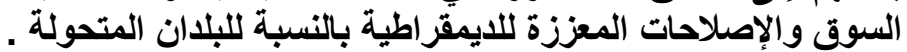

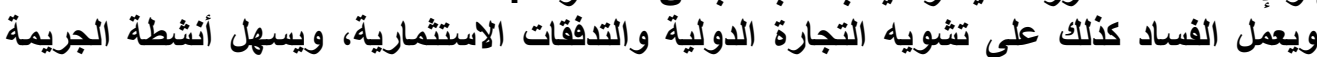

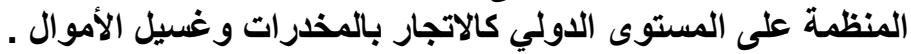

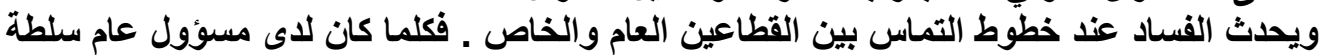

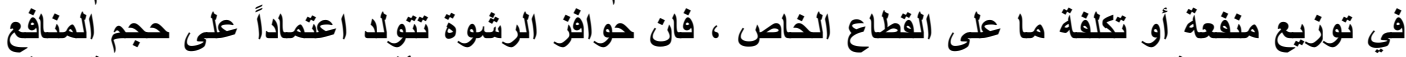

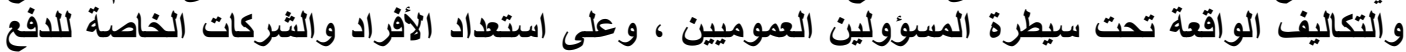

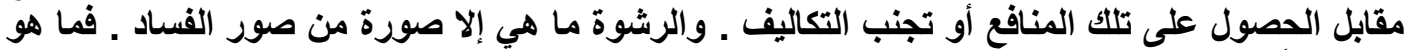
الفساد إذاً ؟

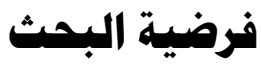

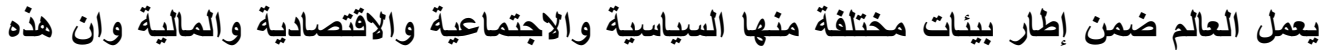

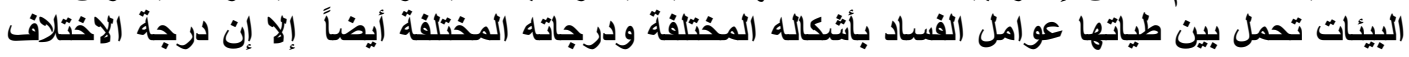

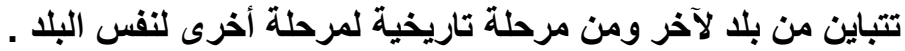

هدف البحث

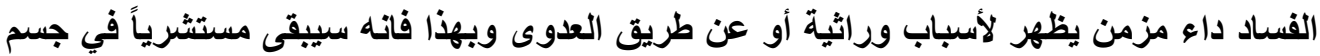

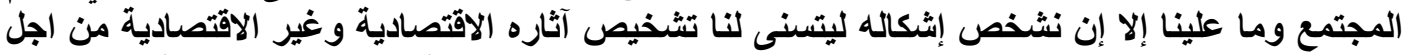

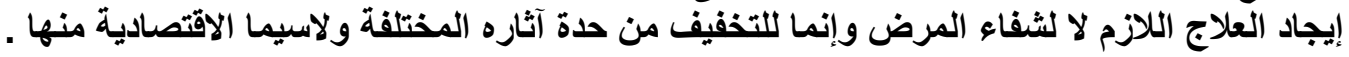

هشكلة البحث

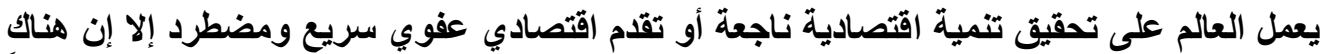

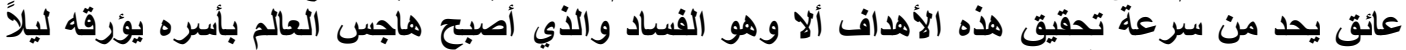

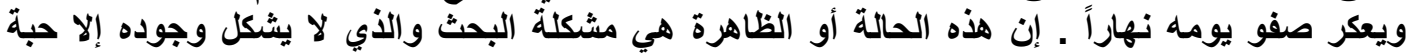

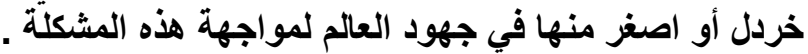

هفهوم الفنساد

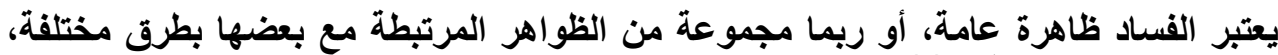

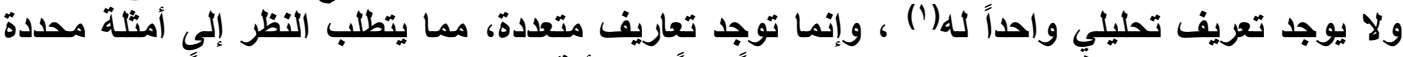

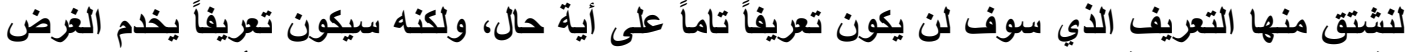

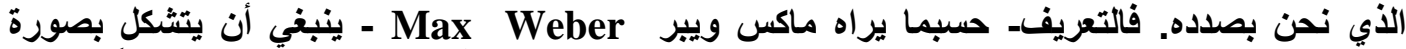

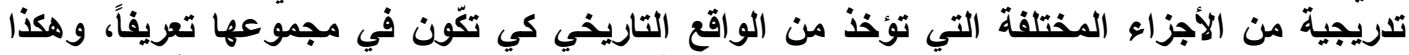

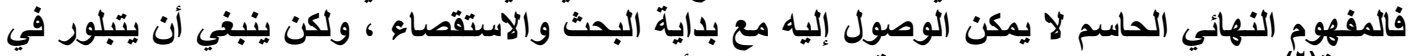

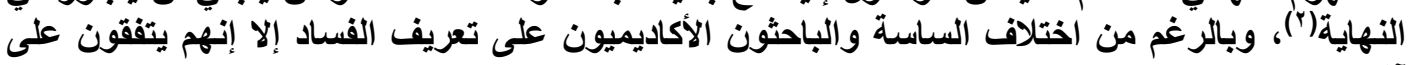
آثاره ونتائجه . 
وردت عبارة (الفساد) وتعريفاتها في خمسين آية، كما وردت أمثال ذلك العدد من الآيات تتناول

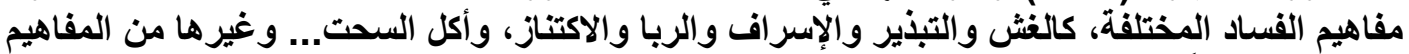

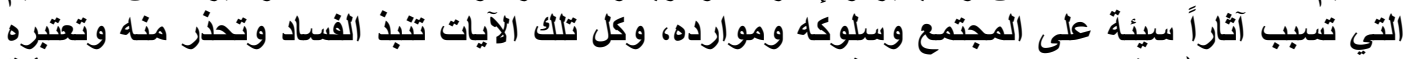

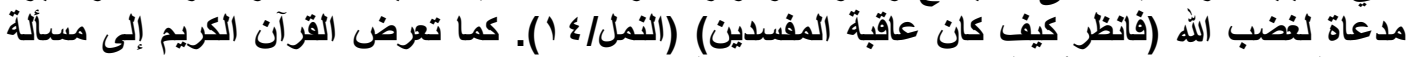

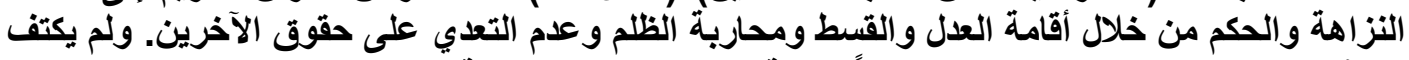

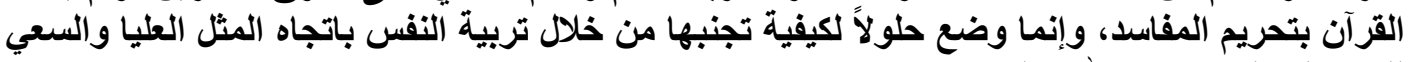

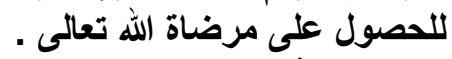

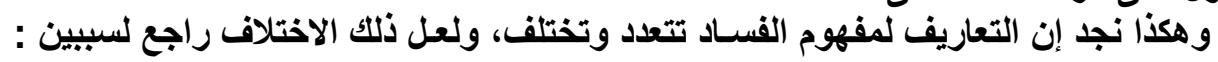

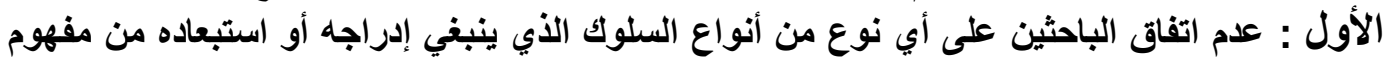

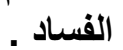

الثاني : اختلاف الثقافة من بلد لآخر، وكذا القوانين والأعراف الاجتماعية التي تجيز سلوكيات معينة

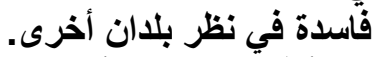

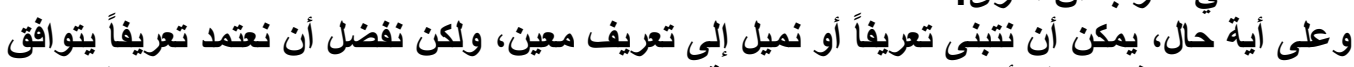

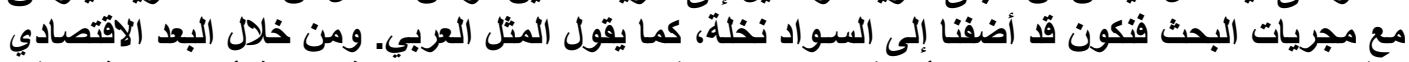

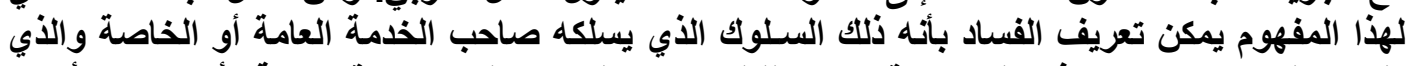

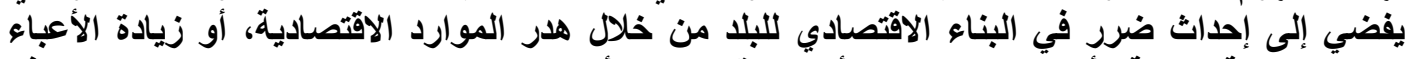

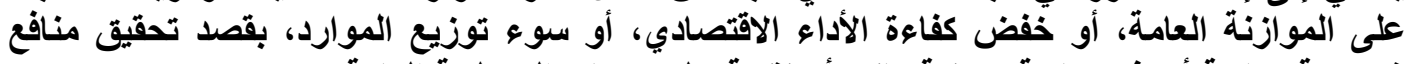

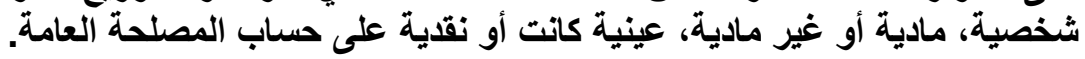

\section{أشكال الفنساد}

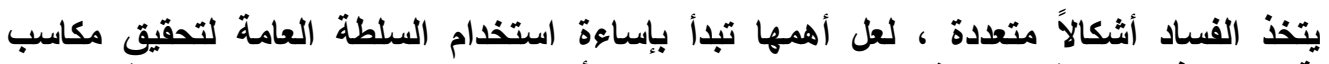

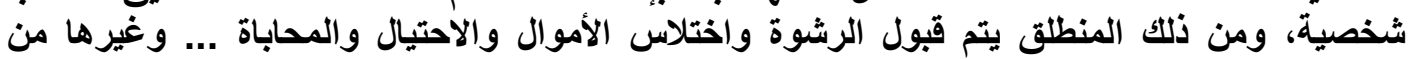

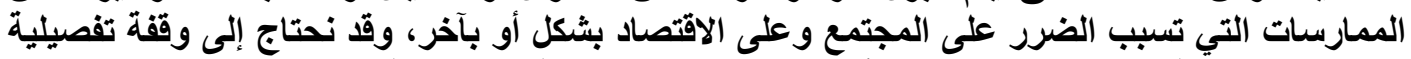

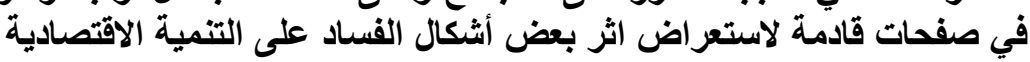

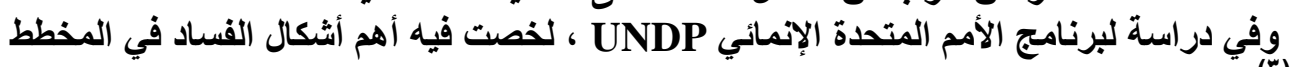




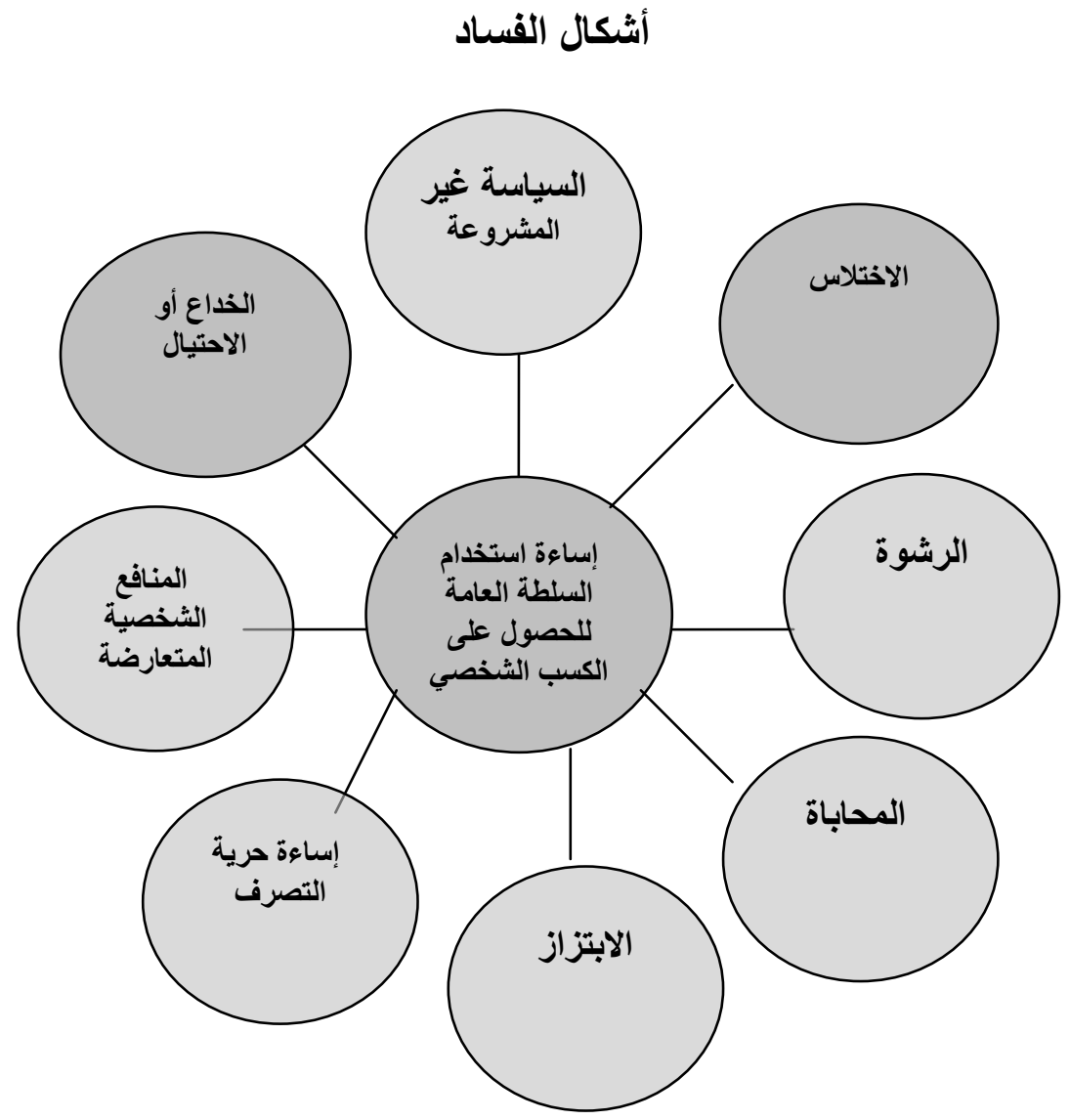

Old Dynamics of Corruption, The Role of the United Nations : المصدر Helping Member States , Build Integrity to curb Corruption, CICP-3,Vienna, Oct ,2002,pp.3 .

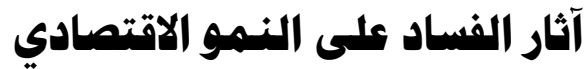

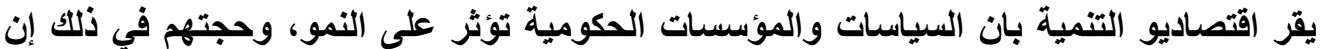

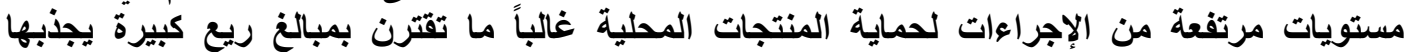

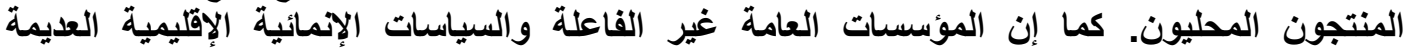

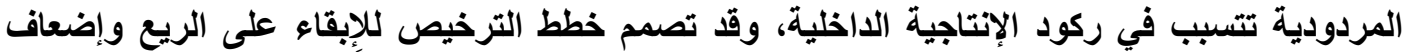

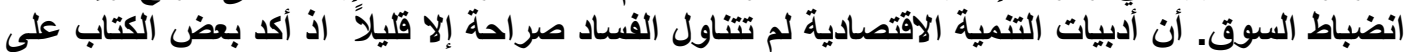

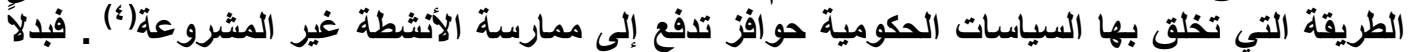

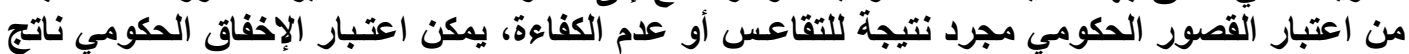

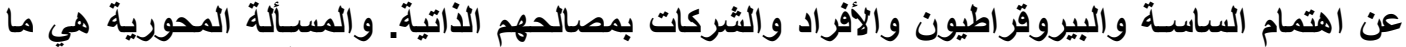

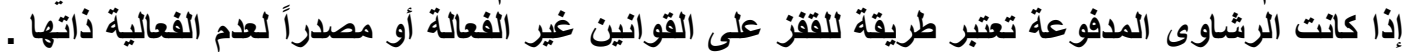

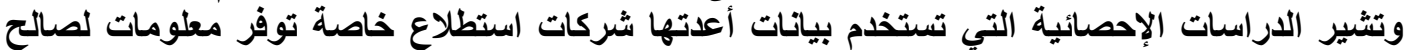

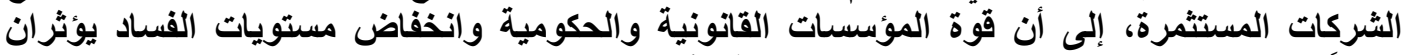

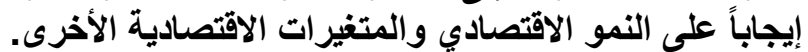

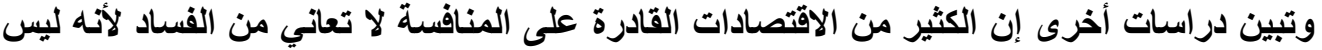

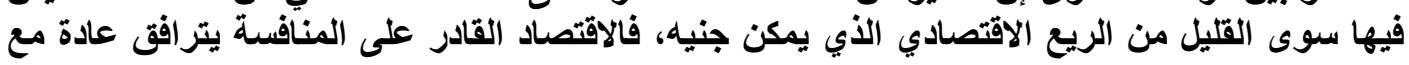


فرص محدودة للتخل الحكومي وهذا يعطيه حرية أكبر للنشاط وتحقيق الأرباح، إذ أن فرص استغلال

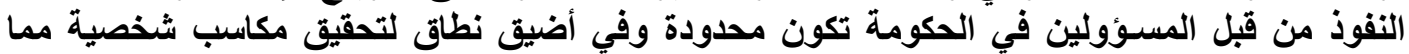

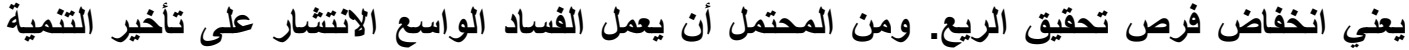

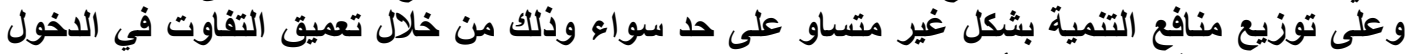

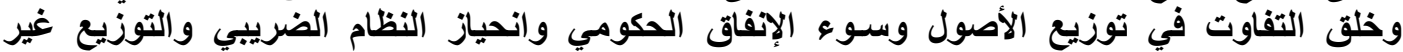

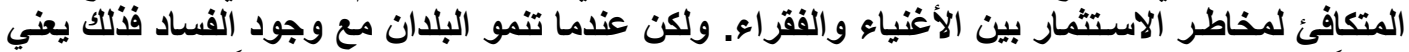

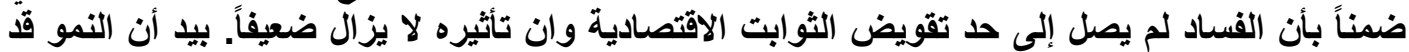

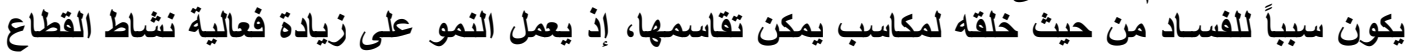

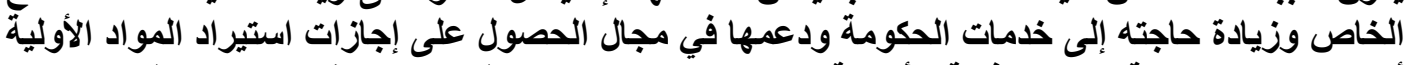

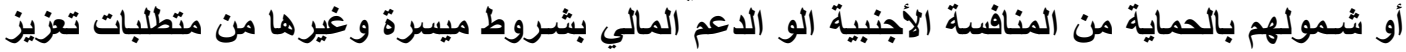

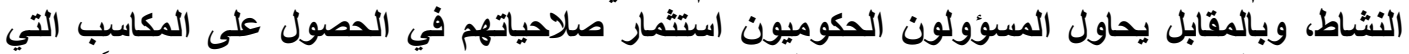

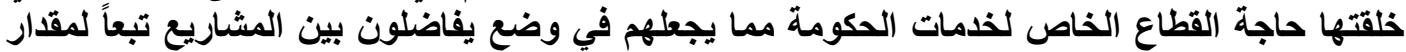

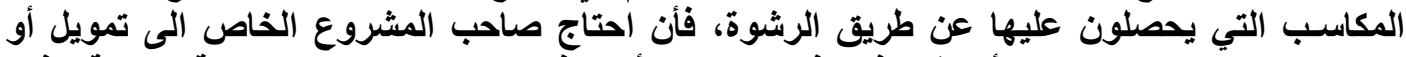

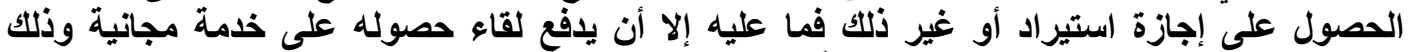

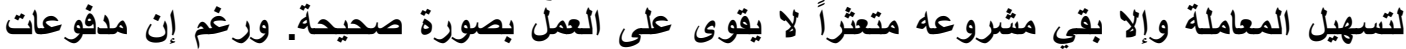

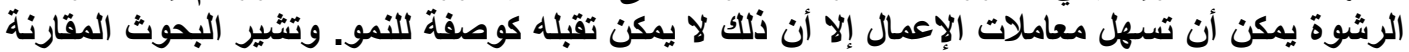

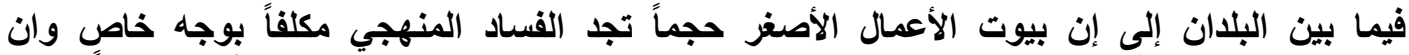

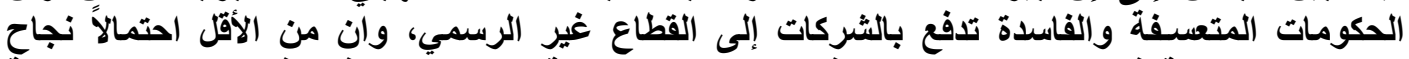

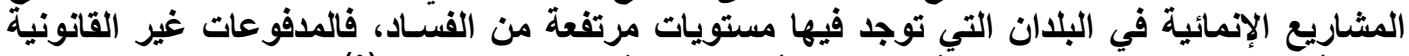

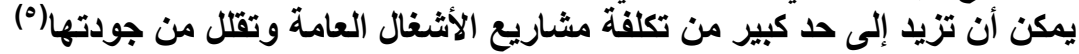

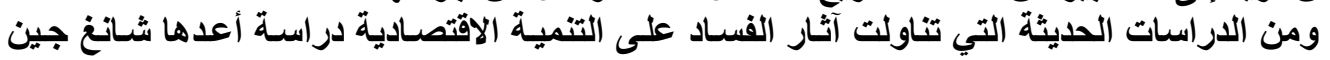

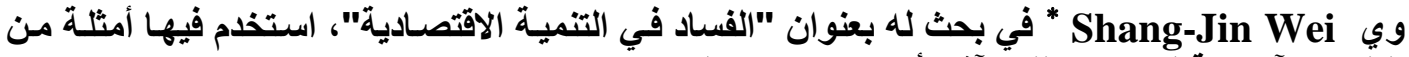

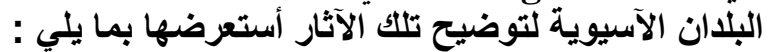

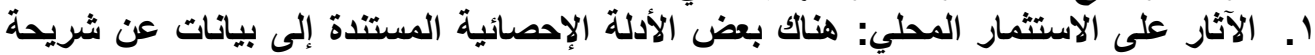

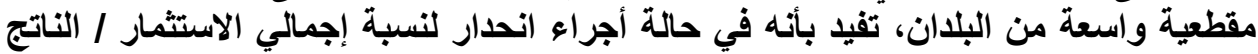

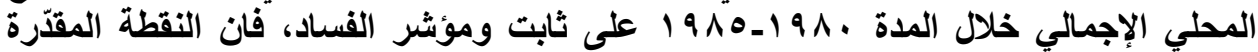

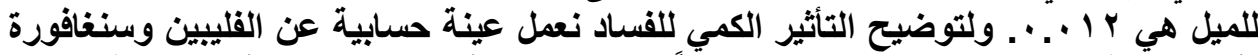

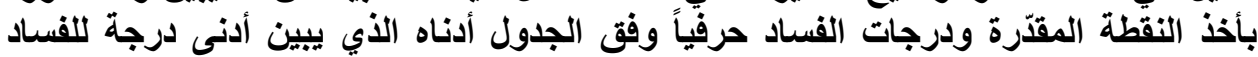

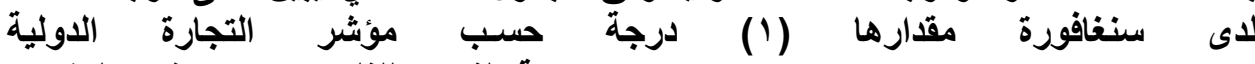
Business International Index (BI)

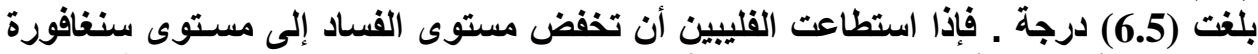

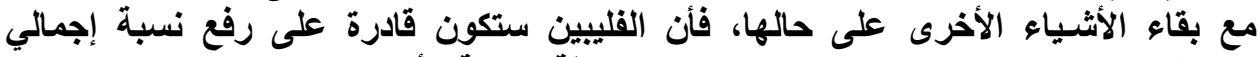

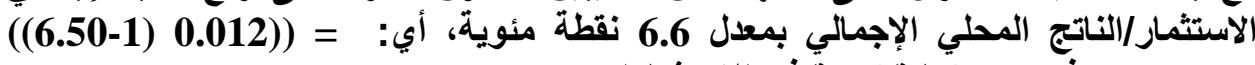
0.066 ـ وهذه تعتبر زيادة كبيرةً في الاستثمارات . 


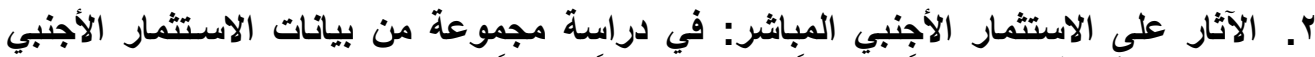

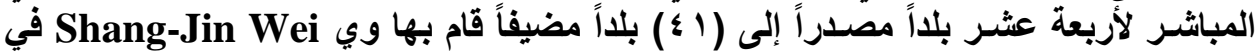

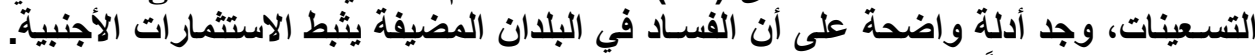

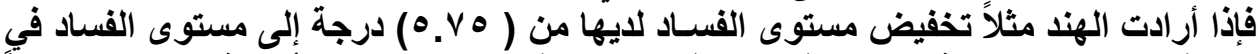

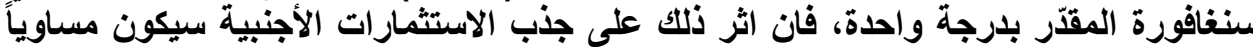

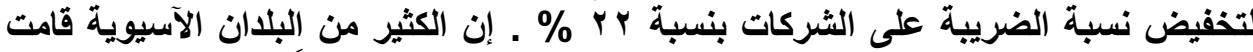

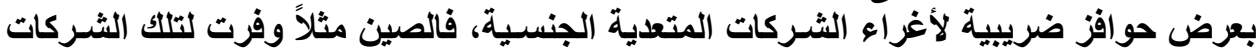

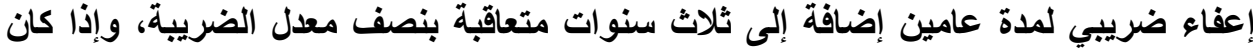

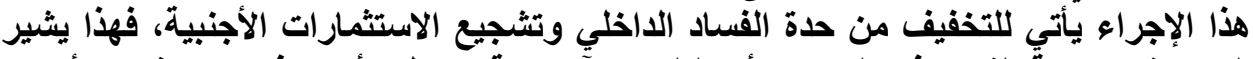

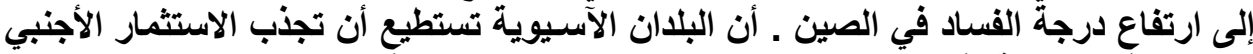

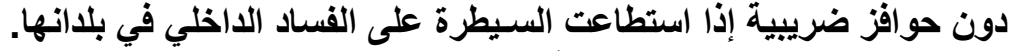

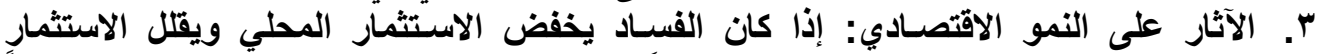

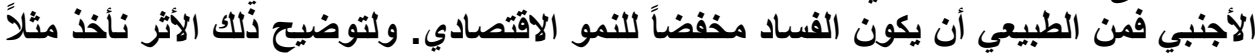

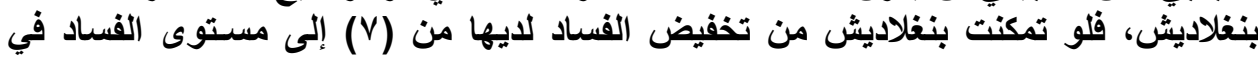

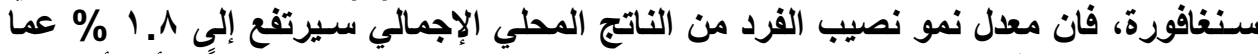

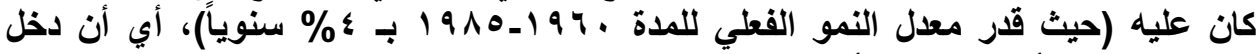

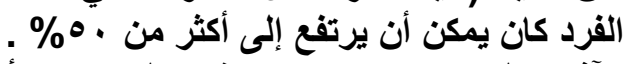

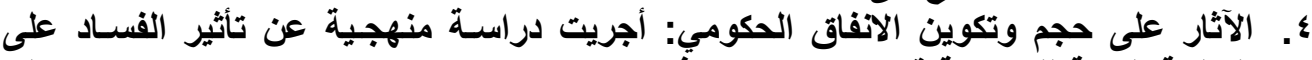

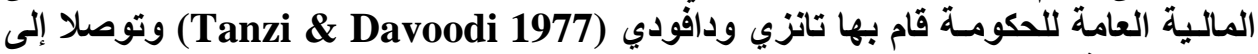

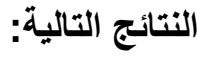

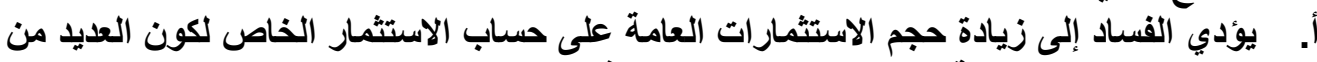

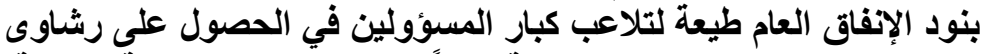

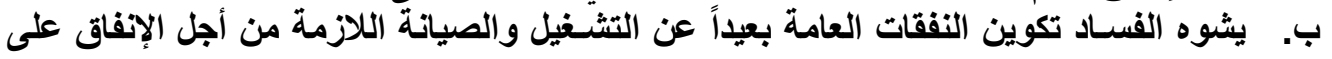

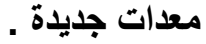
ت. يشوه الفساد تكوين النفقات العامة بعيداً عن حاجة الصحة والتعليم للتمويل، لان هذه التهي النفقات

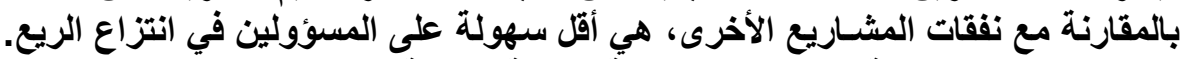

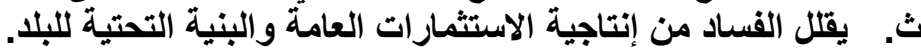

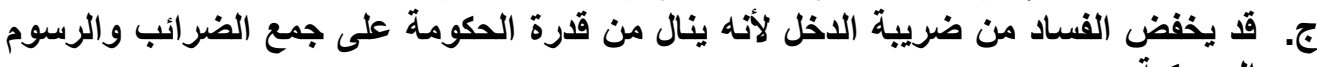

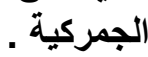

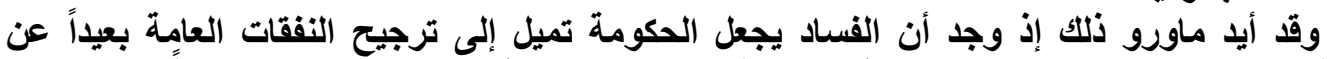

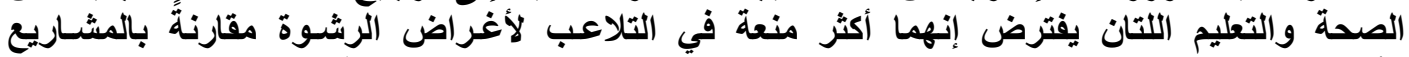

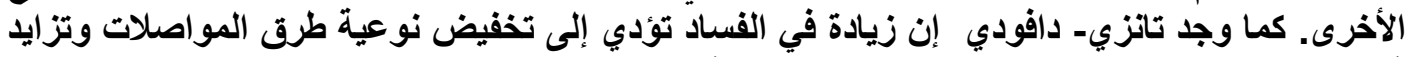

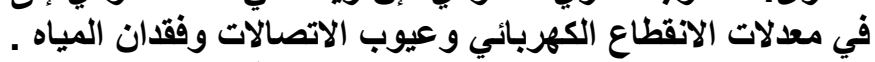

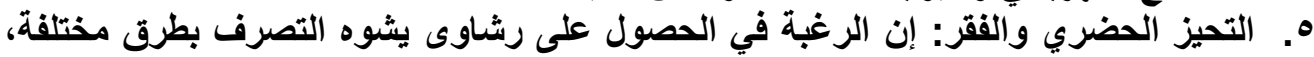

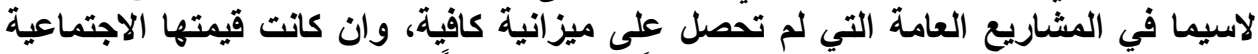

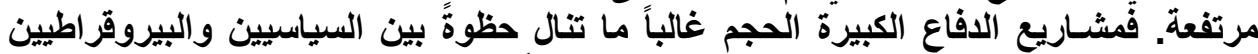

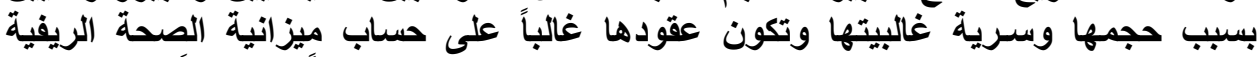

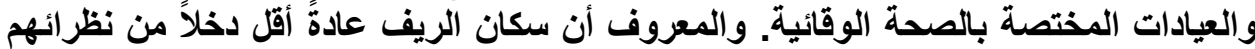

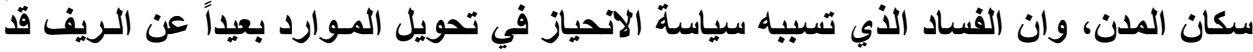

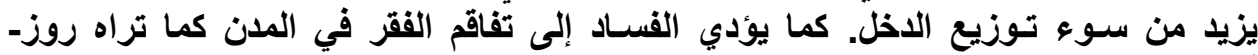

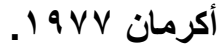

تقديرات الفساد لبلدان مختارة

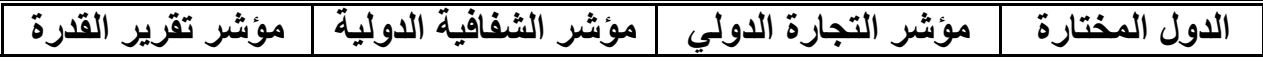




\begin{tabular}{|c|c|c|c|}
\hline التنافسية العالمي & TI97 & $\overline{\text { BI }}$ & \\
\hline \multicolumn{4}{|r|}{ دول أسيوية } \\
\hline $1 . V V$ & Y.rE & 1 & سنغافورة \\
\hline P.IV & r.VY & $r$ & هونغ كونغ \\
\hline 9.97 & $\varepsilon . \varepsilon r$ & Y. Yo & اليابان \\
\hline$\varepsilon .7$ & 0.91 & $\varepsilon$. Yo $_{0}$ & تايوان \\
\hline $0.7 \mathrm{~V}$ & 0.99 & 0 & ماليزيا \\
\hline $7 . Y$ & 7.81 & 0.10 & كوريا الشمالية \\
\hline$V .94$ & $V .9 \leq$ & 9.0 & تايلاند \\
\hline$V .9 \leq$ & $V .90$ & 7.0 & القليبين \\
\hline 0.17 & $\Lambda .1 \mathrm{r}$ & n.a. & الصين \\
\hline$V . r$ & $\Lambda . Y^{\circ}$ & 0.10 & اللهزد \\
\hline$V .9 \leq$ & $\Lambda . Y \wedge$ & 9.0 & اندونيسيا \\
\hline n.a. & $\Lambda . \leqslant V$ & $\mathrm{~V}$ & باكستان \\
\hline n.a. & 9.1 & $\mathrm{~V}$ & بنغلادش \\
\hline \multicolumn{4}{|r|}{ دول غير آسيوية } \\
\hline Y.rV & 1.9 & 1 & كندا \\
\hline 1.94 & $Y . V Y$ & 1.80 & المملكة المتحدة \\
\hline 9.71 & Y.VV & 1.0 & ألمانيا \\
\hline$Y . \& 1$ & r.rq & 1 & الولايات المتحدة \\
\hline$r .01$ & $\varepsilon . \mu \varepsilon$ & 1 & فرنسا \\
\hline $7 . Y \varepsilon$ & $\Lambda . \mu \varepsilon$ & V.Vo & المكسيك \\
\hline n.a. & $\Lambda . \vee$ & 7.0 & كينيا \\
\hline$V . \& 1$ & $\Lambda . V V$ & 7.0 & كولومبيا \\
\hline 8.71 & $\Lambda . \vee \mu$ & n.a. & روسيا \\
\hline n.a. & $9 . Y \leq$ & $\Lambda$ & نيجيريا \\
\hline
\end{tabular}

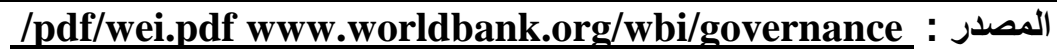

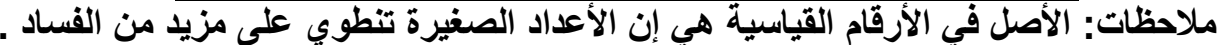

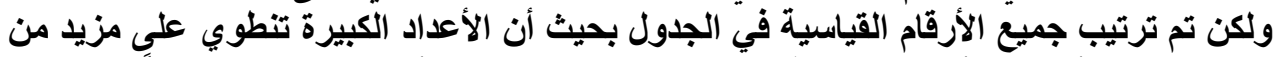

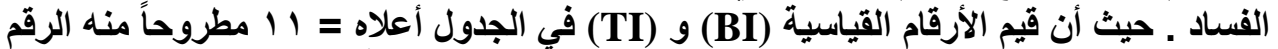

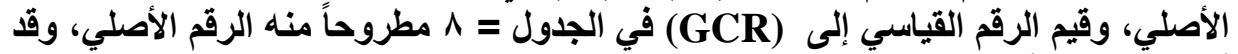

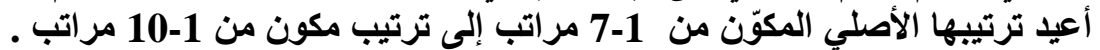

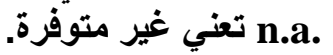


خلاصة المؤشرات (B1) و (T!) و (GCR) في الملحق

حيث أن الفقراء لايهم وسائل أقل في رشوة المسؤولين والسلطة السياسية بثكل عام، لذا فهم

يتعرضون للأضرار التالية جراء ألفئر الفئاد:

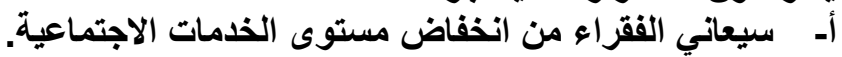

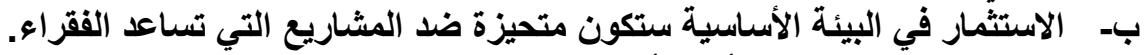

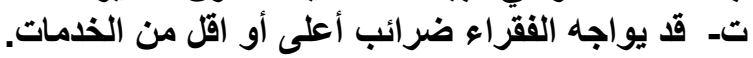

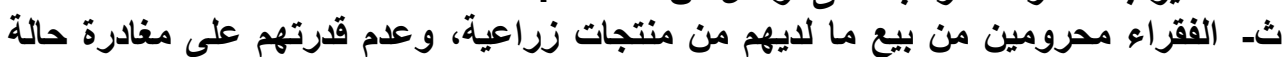

الفقر باستخدام المشاريع الأهلية صغيرة الحجم، إضافة إلى تقليل فرص مصند التعليم للفقراء.

\section{الملحق}

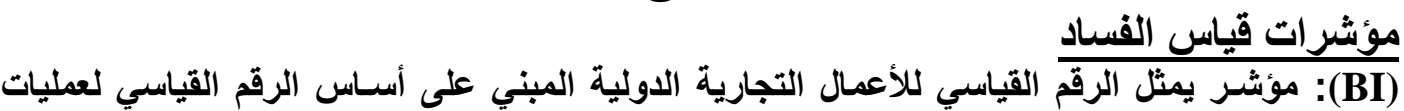

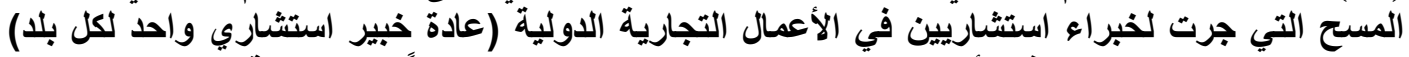

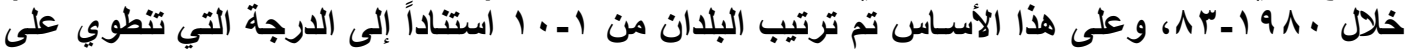

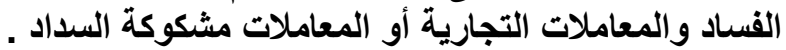
(GCR)

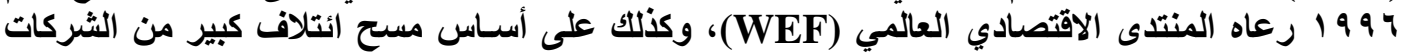

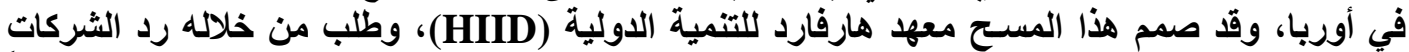

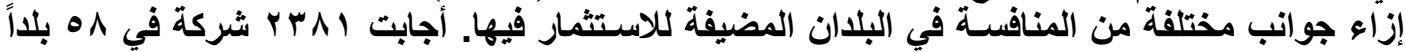

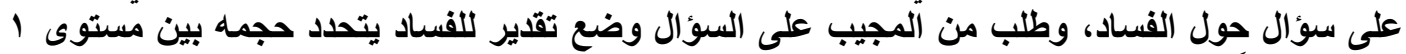

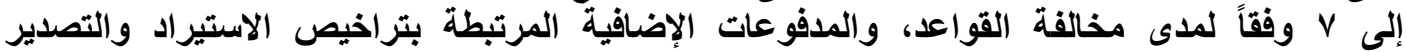

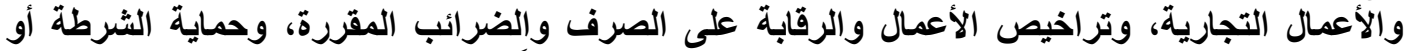
طلبات الحصول على القروض، ومؤشر الفساد لبلآ معين وفقاً لذلك هو متوسط جميع المستجيبين للتقديرات لذلك البلا.

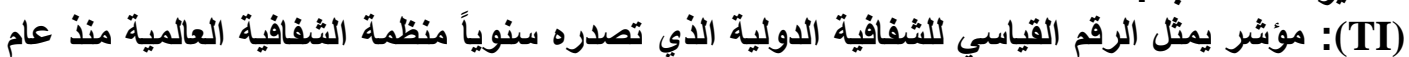

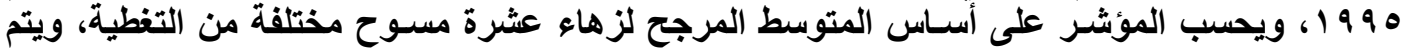

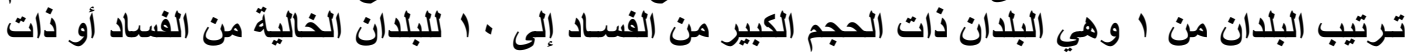

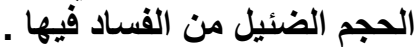

Vito Tanzi , Hamid R Davoodi Corruption, Public Investment , and Growth ,IMF Working Paper No.97/139 . 
أبعاد الفساد الاقتصادي في عملية التنمية

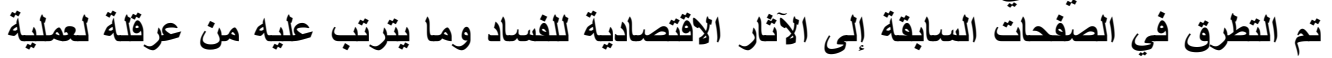

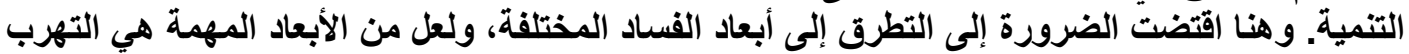

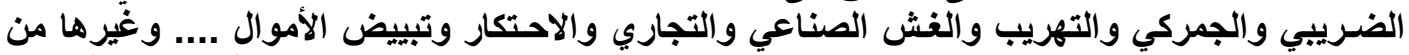

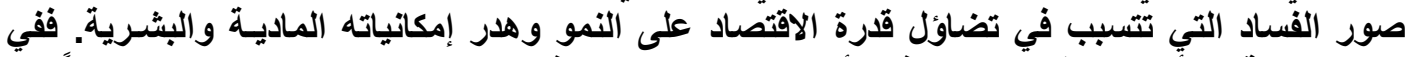

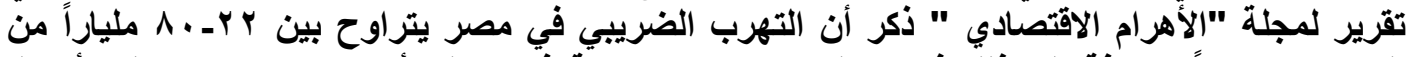

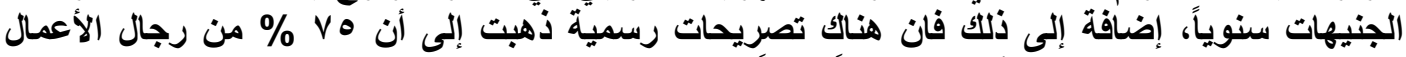

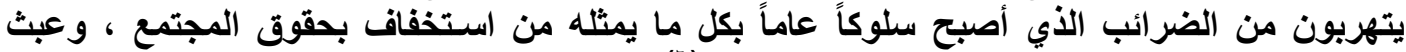

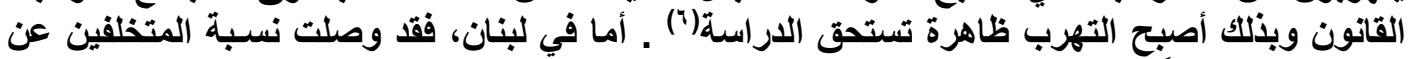

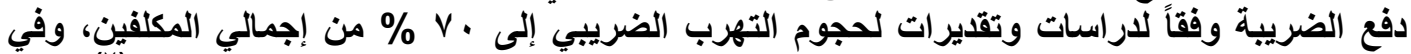

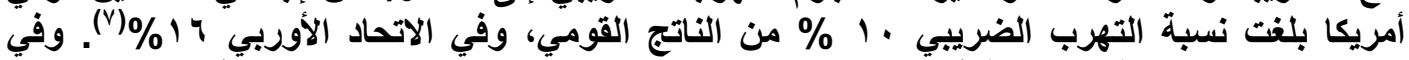

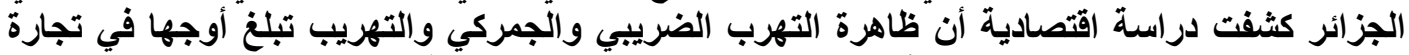

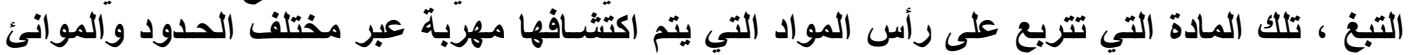

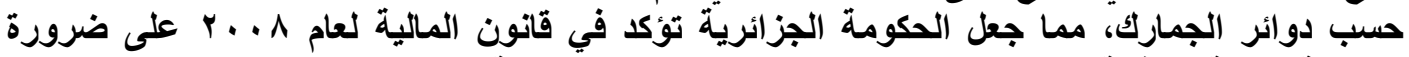

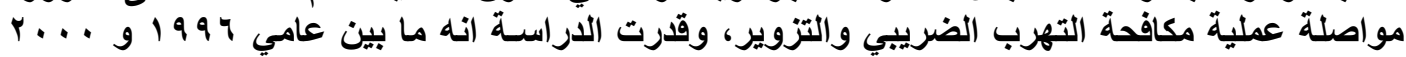

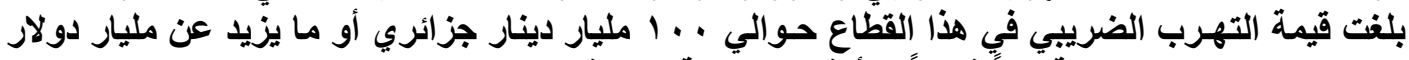

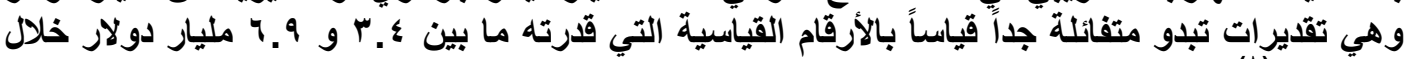

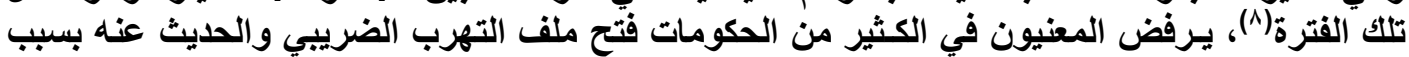

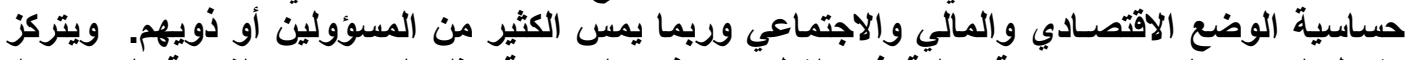

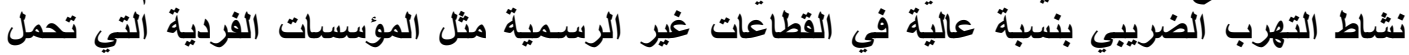

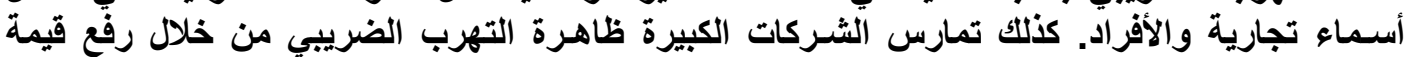

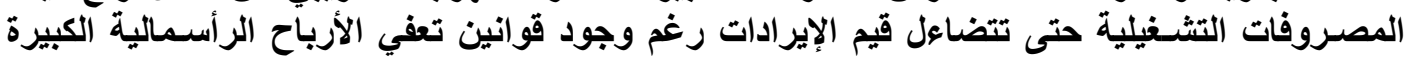

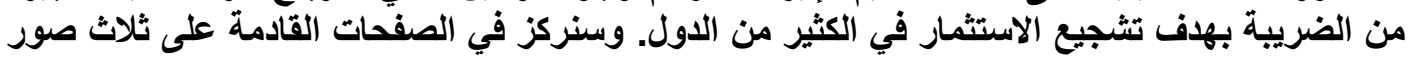

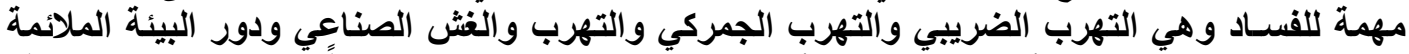

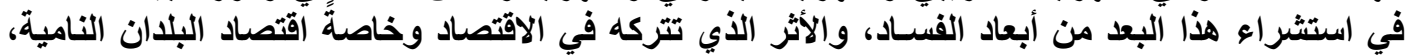

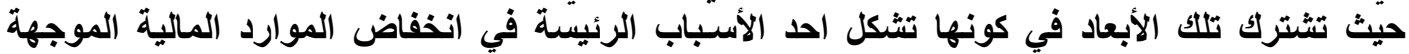

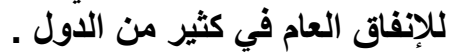




$$
\text { أولاً: التهرب الضريبي }
$$

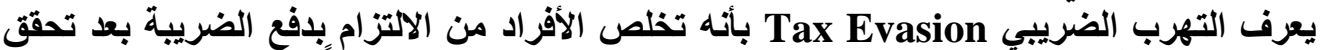

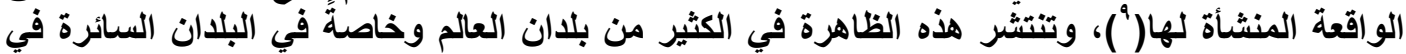

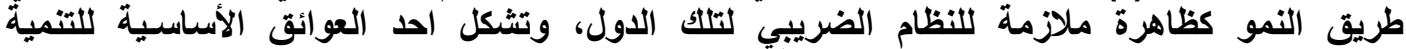

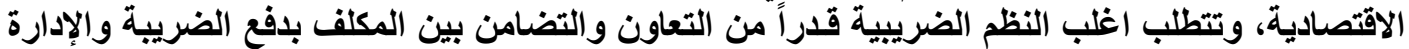

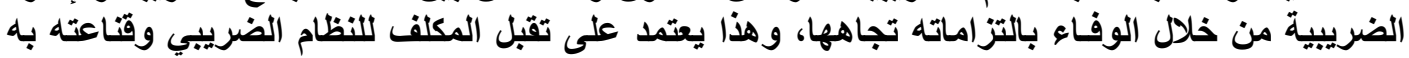

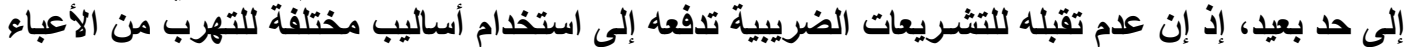

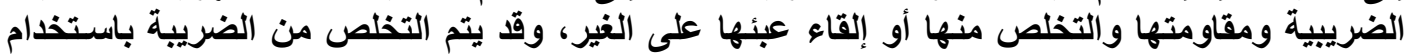

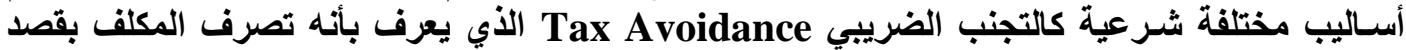

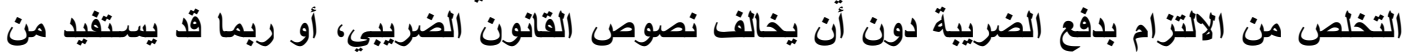

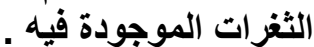

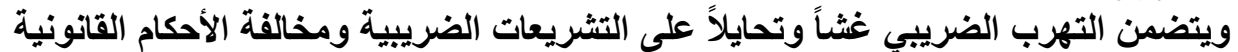

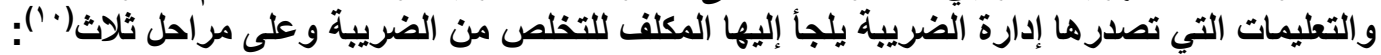

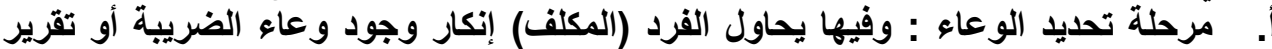

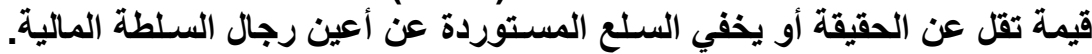

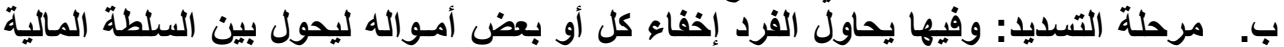

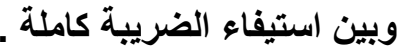

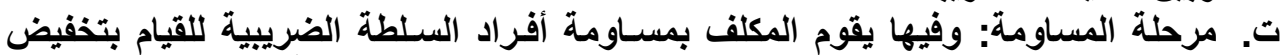

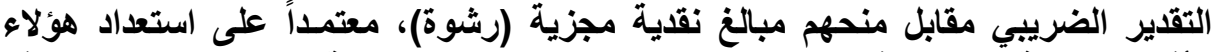

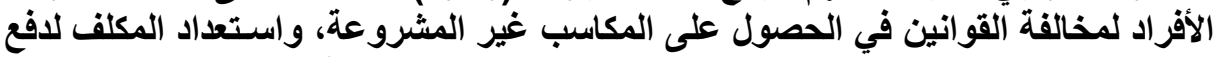

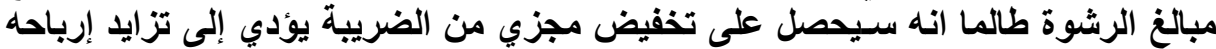

علاقة التهرب الضريبي بالفساد

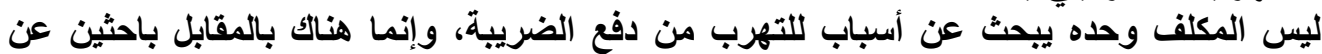

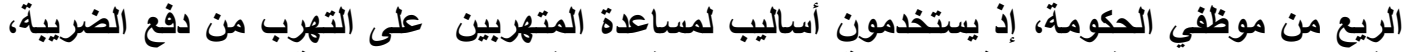

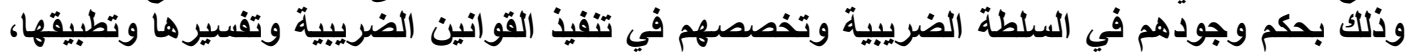

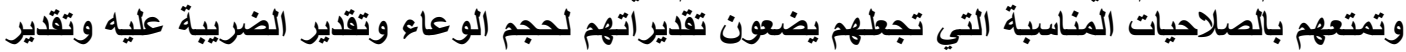

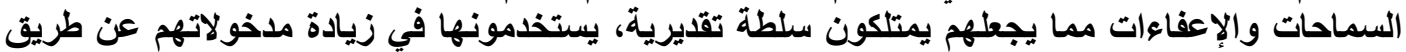

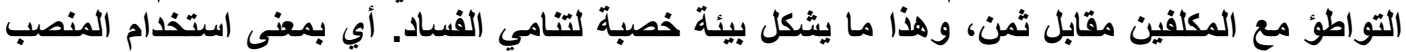

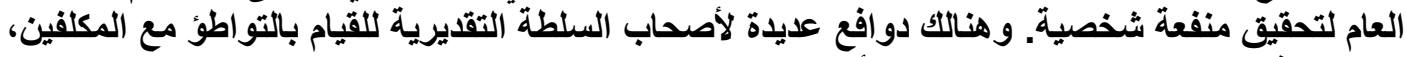

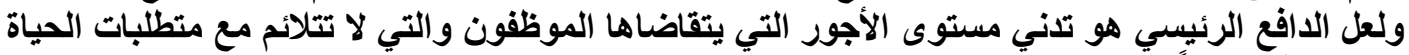

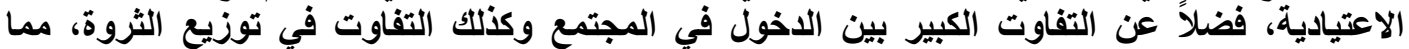

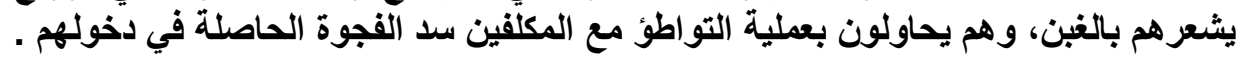




$$
\text { ثاتياً: التهرب الجمركي }
$$

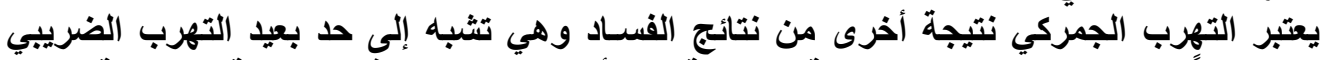

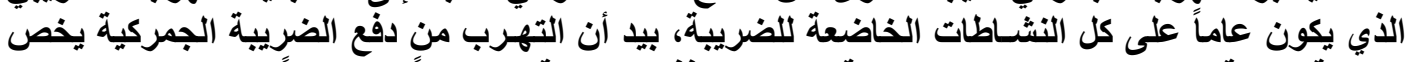

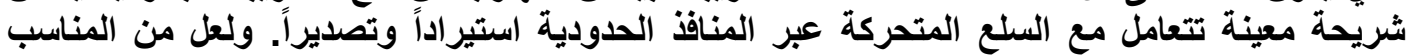
التطرق إلى علاقة التهرب الجمركي بالفساد، الآثار الاقتصسادية للتهرب الضرئية الضريبي والجمركي، وآثاري

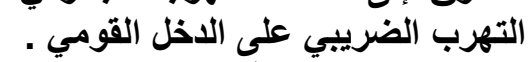

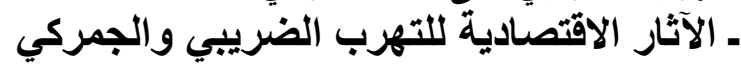

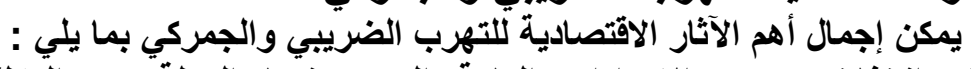

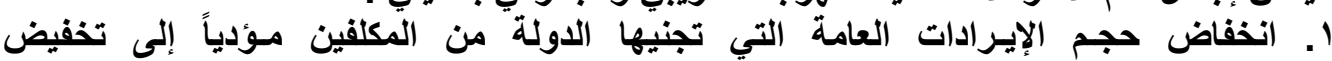

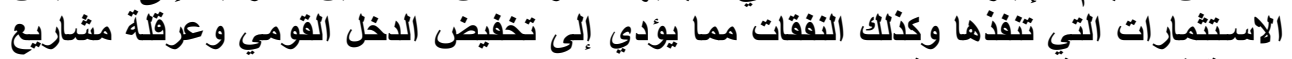

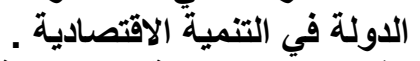
r. رفع سـر الضريبة المفروضة وفية وفرض ضريبة جديدة لتعويض الحكومة عن النقص الحاصل

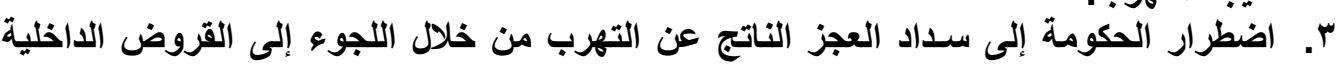

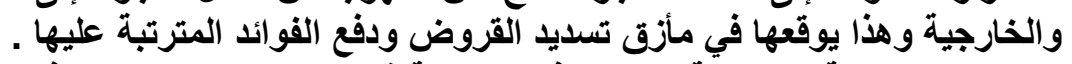

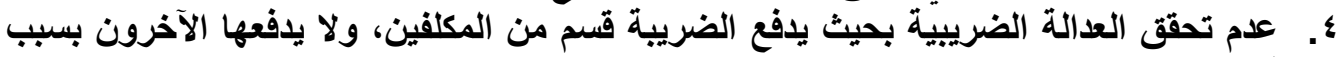
قارتهم على التهرب.

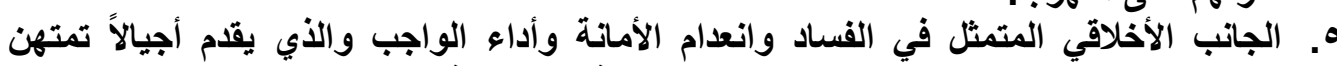
الاحتيال والنصب والتلاعب على القوانين وإثـاعة تقبل حالة الفسـاد عند المجتمع والآنسجام الأنس

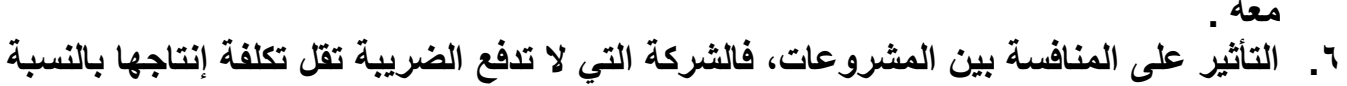

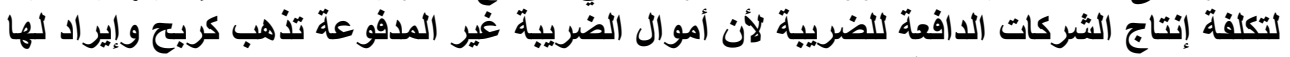

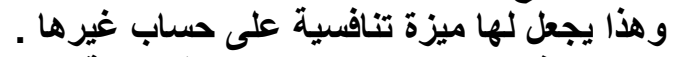

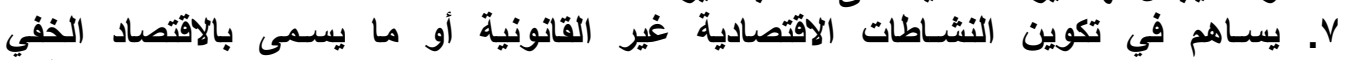

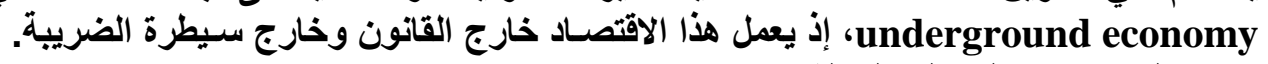
ـ أثر التهرب الضريبي على الاخل القومي إلتمل يمكن قياس الآثار ألاقتصادية للخسارة المالية التية للاولة الناجمة عن التهرب الضريبي والتهريب بشكل

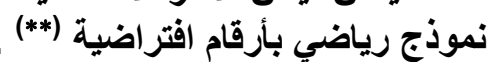

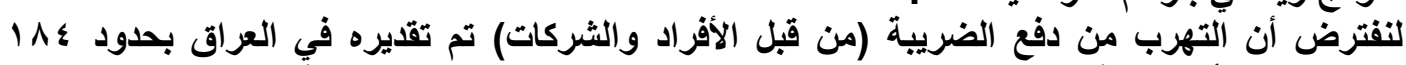

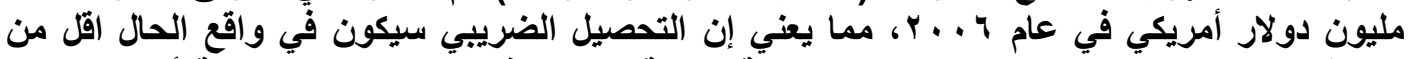

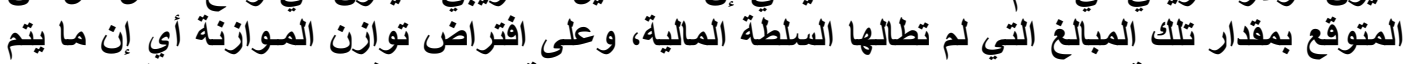

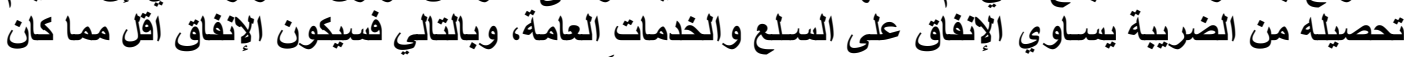

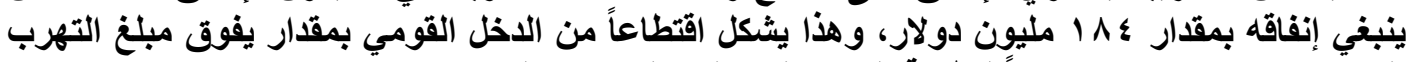

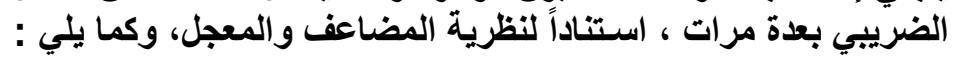


أولاًا : اثر المضاعف الته

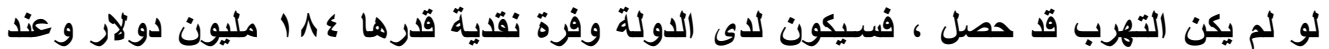

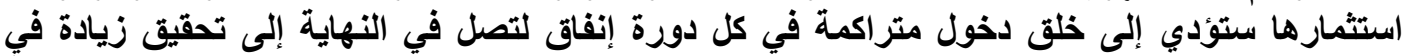

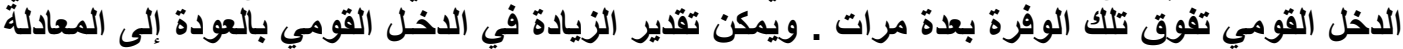
التي تمثل صيغة المضاعف الرياضية وهي :

$$
\mathrm{K}=1 / 1-\mathrm{c}
$$

حيث إن K تمثل المضاعف و c تمثل الميل الحدي للاستهلاك ، فإذا علمنا بان الميل الحدي للاستهلاك يبلغ (0.77) ، سنحصل على النتائج التالية :

$$
\mathrm{K}=1 / 1-\mathrm{c}=1 / 1-0.77=4.3478
$$

بمغنى إن استثمار دولار واحد سيولا بموجب نظرية المضاعف دخلاً قدره 4.35 دولار تقريباً ، أي

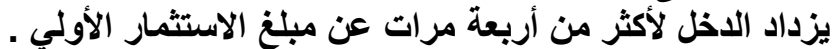

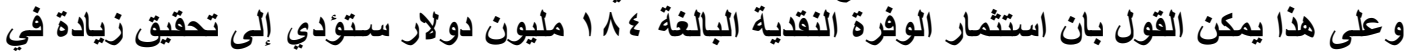

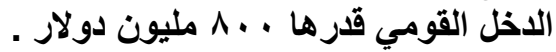
$\Delta Y=184000000 \times 4.3478=800000000$

\begin{tabular}{|c|c|c|}
\hline الاخل & (بملايين الألغلار ات) & الإنفاق \\
\hline دخل المرحلة الأولى & 184000000.00 & الاستثمار الأولي \\
\hline دخل المرحلة الثانية & 141680000.00 & استهولاك المرحلة الأولى \\
\hline دخل المرحلة الثالثة & 109093600.00 & استهلاك المرحلة الثانية \\
\hline دخل المرحلة الرابعة & 84002072.00 & استهلاك المرحلة الثالثة \\
\hline دخل المرحلة الخامسة & 64681595.44 & استهلاك المرحلة الرابعة \\
\hline دخل المرحلة السادسة & 49804828.49 & استهلاك المرحلة الخامسة \\
\hline دخل المرحلة السابعة & 38349717.94 & استهلاك المرحلة السادسة \\
\hline دخل المرحلة الثامنة & 29529282.81 & استهلاك المرحلة السابعة \\
\hline دخل المرحلة التاسعة & 22737547.76 & استهلاك المرحلة الثامنة \\
\hline دخل المرحلة العاشرة & $\mathbf{1 7 5 0 7 9 1 1 . 7 8}$ & استهلاك المرحلة التاسعة \\
\hline دخل المرحلة الحادية عشر & 13481092.07 & استهلاك المرحلة العاشرة \\
\hline دخل المرحلة الثاتية عشر & $\mathbf{1 0 3 8 0 4 4 0 . 8 9}$ & استهلاك المرحلة الحادية عشر \\
\hline دخل المرحلة الثالثة عشر & 7992939.49 & استهلاك المرحلة الثانية عشر \\
\hline دخل المرحلة الرابعة عشر & 6154563.41 & استهلاك المرحلة الثالثة عشر \\
\hline دخل المرحلة الخامسة عشر & 4739013.82 & استهلاك المرحلة الرابعة عشر \\
\hline دخل المرحلة السادسة عشر & 3649040.64 & استهلاك المرحلة الخامسة عشر \\
\hline دخل المرحلة السابعة عشر & 2809761.30 & استهلاك المرحلة السادسة عشر \\
\hline دخل المرحلة الثامنة عشر & 2163516.20 & استهلاك المرحلة السابعة عشر \\
\hline دخل المرحلة التاسعة عشر & 1665907.47 & استهلاك المرحلة الثامنة عشر \\
\hline دخل المرحلة العشرون & 1282748.75 & استهلاك المرحلة التاسعة عشر \\
\hline دخل المرحلة الحادية والعشرون & 987716.54 & استهلاك المرحلة العشرون \\
\hline دخل المرحلة الثانية والعشرون & 760541.74 & استهلاك المرحلة الحادية والعثرون \\
\hline دخل المرحلة الثالثة والعشرون & 585617.14 & استهلاك المرحلة الثانية والعشرون \\
\hline دخل المرحلة الرابعة والعثرون & 450925.20 & استهلاك المرحلة الثالثة والعشرون \\
\hline
\end{tabular}

ولتوضيح الآلية التي تتكون فيها هذه الزيادة في الدخل نستعين بالجدول التالي : 


\begin{tabular}{|c|c|c|}
\hline دخل المرحلة الخامسة والعشرون & 347212.40 & استهلاك المرحلة الرابعة والعشرون \\
\hline دخل المرحلة السادسة والعشرون & 267353.55 & استهلاك المرحلة الخامسة والعشرون \\
\hline دخل المرحلة السابعة والعشرون & 205862.23 & استهلاك المرحلة السادسة والعشرون \\
\hline دخل المرحلة الثامنة والعشرون & 158513.92 & استهلاك المرحلة السابعة والعشرون \\
\hline دخل المرحلة التاسعة والعشرون & 122055.72 & استهلاك المرحلة الثامنة والعشرون \\
\hline دخل المرحلة الثخاثون & 93982.90 & استهلاك المرحلة التاسعة والعشرون \\
\hline دخل المرحلة الحادية والثلاثون & 72366.83 & استهلاك المرحلة الثُلاثون \\
\hline دخل المرحلة الثانية والثلاثون & 55722.46 & استهلاك المرحلة الحادية والثلاثون \\
\hline لدخل المرحلة الثالثة والثلاثون & 42906.30 & استهلاك المرحلة الثانية والثلاثون \\
\hline دخل المرحلة الرابعة والثلاثون & 33037.85 & استهلاك المرحلة الثالثة والثُلاثون \\
\hline دخل المرحلة الخامسة والثلاثون & 25439.14 & استهلاك المرحلة الرابعة والثلاثون \\
\hline دخل المرحلة السادسة والثلاثون & 19588.14 & استهلاك المرحلة الخامسة و الثلاثون \\
\hline دخل المرحلة السابعة والثلاثون & 15082.87 & استهلاك المرحلة السادسة والثلاثون \\
\hline دخل المرحلة الثامنة والثُلاثون & 11613.81 & استهلاك المرحلة السابعة والثلاثون \\
\hline دخل المرحلة التاسعة والثلاثون & 8942.63 & استهلاك المرحلة الثامنة والثلاثون \\
\hline دخل المرحلة الأربعون & 6885.83 & استهلاك المرحلة التاسعة والثلاثون \\
\hline دخل المرحلة الحادية والأربعون & 5302.09 & استهلاك المرحلة الأربعون \\
\hline دخل المرحلة الثانية والأربعون & 4082.61 & استهلاك المرحلة الحادية والأربعون \\
\hline دخل المرحلة الثالثة والأربعون & 3143.61 & استهلاك المرحلة الثانية والأربعون \\
\hline دخل المرحلة الرابعة والأربعون & 2420.58 & استهلاك المرحلة الثالثة والأربعون \\
\hline دخل المرحلة الخامسة والأربعون & 1863.84 & استهلاك المرحلة الرابعة والأربعون \\
\hline دخل المرحلة السادسة والأربعون & 1435.16 & استهلاك المرحلة الخامسة والأربعون \\
\hline دخل المرحلة السابعة والأربعون & 1105.07 & استهلاك المرحلة السادسة والأربعون \\
\hline دخل المرحلة الثامنة والأربعون & 850.91 & استهلاك المرحلة السابعة والأربعون \\
\hline دخل المرحلة التاسعة والأربعون & 655.20 & استهلاك المرحلة الثامنة والأربعون \\
\hline دخل المرحلة الخمسون & $\mathbf{5 0 4 . 5 0}$ & استهلاك المرحلة التاسعة والأربعون \\
\hline دخل المرحلة الحادية والخمسون & 388.47 & استهلاك المرحلة الخمسون \\
\hline دخل المرحلة الثاتية والخمسون & 299.12 & استهلاك المرحلة الحادية والخمسون \\
\hline دخل المرحلة الثالثة والخمسون & 230.32 & استهلاك المرحلة الثانية والخمسون \\
\hline دخل المرحلة الرابعة والخمسون & $\mathbf{1 7 7 . 3 5}$ & استهلاك المرحلة الثالثة والخمسون \\
\hline لدخل المرحلة الخامسة والخمسون & 136.56 & استهلاك المرحلة الرابعة والخمسون \\
\hline لذخل المرحلة السادسة والخمسون & $\mathbf{1 0 5 . 1 5}$ & استهلاك المرحلة الخامسة والخمسون \\
\hline دخل المرحلة السابعة والخمسون & 80.97 & استهلاك المرحلة السادسة والخمسون \\
\hline دخل المرحلة الثامنة والخمسون & 62.34 & استهلاك المرحلة السابعة والخمسون \\
\hline دخل المرحلة التاسعة والخمسون & 48.00 & استهلاك المرحلة الثامنة والخمسون \\
\hline دخل المرحلة الستون & 36.96 & استهلاك المرحلة التاسعة والخمسون \\
\hline دخل المرحلة الحادية والستون & 28.46 & استهلاك المرحلة الستون \\
\hline دخل المرحلة الثانية والستون & 21.92 & استهلاك المرحلة الحادية والستون \\
\hline لخل المرحلة الثالثة والستون & 16.87 & استهلاك المرحلة الثانية والستون \\
\hline دخل المرحلة الرابعة والستون & 12.99 & استهلاك المرحلة الثالثة والستون \\
\hline دخل المرحلة الخامسة والستون & $\mathbf{1 0 . 0 1}$ & استهلاك المرحلة الرابعة والستون \\
\hline دخل المرحلة السادسة والستون & 7.70 & استهلاك المرحلة الخامسة والستون \\
\hline دخل المرحلة السابعة والستون & 5.93 & استهلاك المرحلة السادسة والستون \\
\hline لدخل المرحلة الثامنة والستون & 4.57 & استهلاك المرحلة السابعة والستون \\
\hline دخل المرحلة التاسعة والستون & 3.52 & استهلاك المرحلة الثامنة والستون \\
\hline دخل المرحلة السبعون & 2.71 & استهلاك المرحلة التاسعة والستون \\
\hline
\end{tabular}




\begin{tabular}{|c|c|c|}
\hline دخل المرحلة الحادية والسبعون & 2.09 & استهلاك المرحلة السبعون \\
\hline دخل المرحلة الثانية والسبعون & 1.61 & استهلاك المرحلة الحادية والسبعون \\
\hline دخل المرحلة الثالثة والسبعون & 1.24 & استهلاك المرحلة الثانية والسبعون \\
\hline دخل المرحلة الرابعة والسبعون & 0.95 & استهلاك المرحلة الثالثة والسبعون \\
\hline دخل المرحلة الخامسة والسبعون & 0.73 & استهلاك المرحلة الرابعة والسبعون \\
\hline دخل المرحلة السادسة والسبعون & 0.56 & استهلاك المرحلة الخامسة والسبعون \\
\hline دخل المرحلة السابعة والسبعون & 0.43 & استهلاك المرحلة السادسة والسبعون \\
\hline دخل المرحلة الثامنة والسبعون & 0.33 & استهلاك المرحلة السابعة والسبعون \\
\hline دخل المرحلة التاسعة والسبعون & 0.26 & استهلاك المرحلة الثامنة والسبعون \\
\hline & 799999999.14 & المجموع \\
\hline
\end{tabular}

دليل الجدول

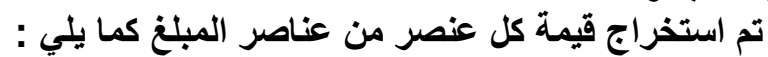
قيمة العنصر في الزمن t = قيمة العنصر في الزمن (t-1) مضروياً في الميل العدي للاستهلاك .

يلاحظ من هذا الجدول إن الإنفاق بدأ من مبلغ 184مليون دولار والذي تحول بالكامل إلى دخل

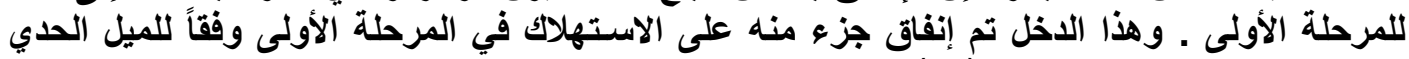

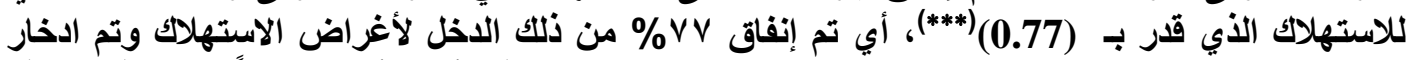

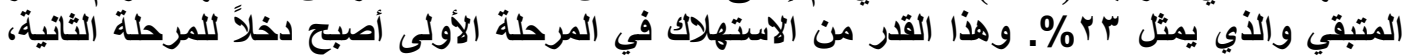

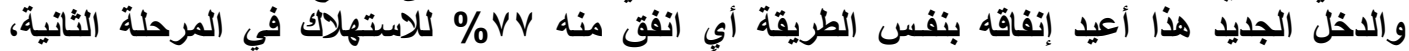

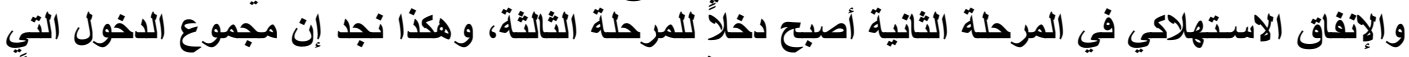
ولاها الإنفاق الاستهلاكي بعد ثمان وسبعين مرحلة للاستهلاك وصلئ وصل إلى (799999999.14) دولاراً،

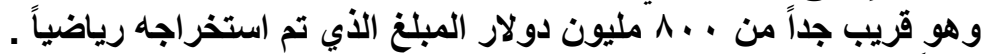

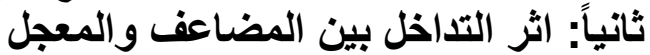

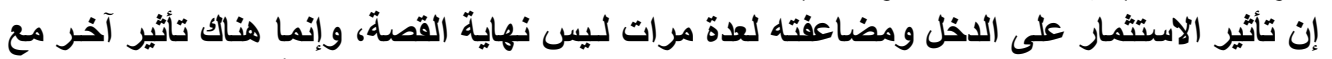

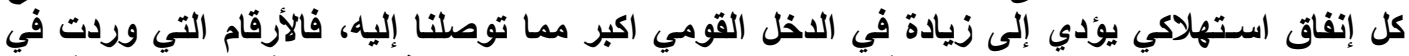

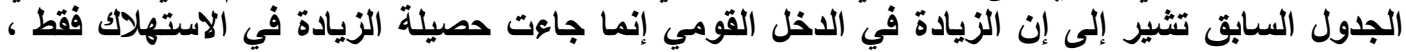

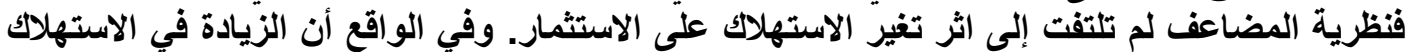

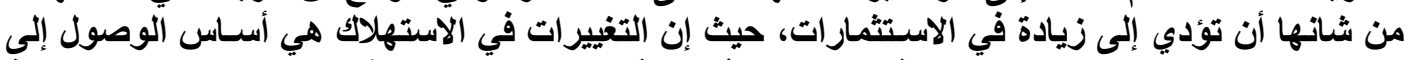

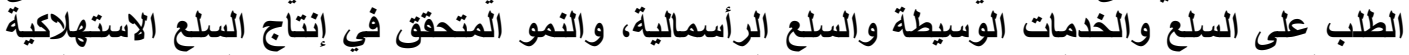

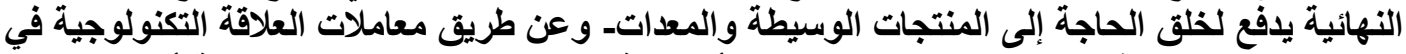

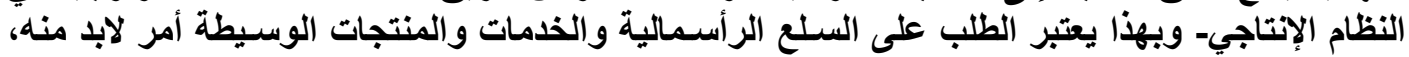

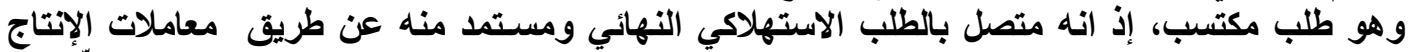

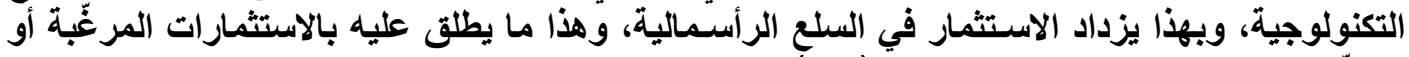
المولَّة Induced Investment والاستثمارات المولّدة يطلق عليها بالمعجل Accelerator سنلاحظ أن الزيادة في الاخل القومي تزيد عن (800) مليون دولار وذلكل بتأثير زيادة حجم الاستثمارات

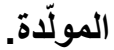


ويمكن توضيح ذلك باستخدام النماذج الرياضية التالية(' ('):

$$
\begin{aligned}
& \mathbf{R}=\mathbf{I} / \mathbf{O} \\
& \mathbf{R}=\Delta \mathbf{I} / \Delta \mathbf{O} \\
& \Delta \mathbf{I}=\Delta \mathbf{O} \times \mathbf{R}
\end{aligned}
$$

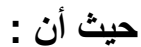

Capital / Output Ratio. تمثل نسبة رأس المال للإنتاج: R

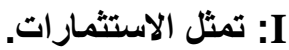

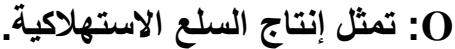

$$
\mathbf{M}_{\mathrm{t}}=\mathbf{R O}_{\mathrm{t}}
$$

ويمكن كتابتها بصيغة أخرى :

$$
\begin{aligned}
\mathbf{I}_{\mathbf{t}} & =\mathbf{M}_{\mathbf{t}}-\mathbf{M}_{\mathrm{t}-1} \\
& =\mathbf{R O} \mathbf{O}_{\mathbf{t}}-\mathbf{R O}_{\mathrm{t}-1} \\
& =\mathbf{R}\left(\mathbf{O t}-\mathbf{O}_{\mathrm{t}-1}\right)
\end{aligned}
$$

1: M تمثل رأس المال اللازم للاستثمار (المكائن والآلات ) .

\begin{tabular}{|c|c|c|c|c|}
\hline الدخل القومي & $\begin{array}{c}\text { الاستهلاك } \\
\text { C }\end{array}$ & الاستثمارات & الأصتيةارات & الفترة الزمنية \\
\hline 184.000 .000 & $\mathbf{0}$ & $\mathbf{0}$ & 184.000 .000 & $\mathbf{0}$ \\
\hline 387.280 .000 & 141.680 .000 & 61.600 .000 & 184.000.000 & 1 \\
\hline 550.260 .209 & 298.205 .600 & 68.054 .609 & 184.000 .000 & 2 \\
\hline 662.263 .300 & 423.700 .361 & 54.562 .939 & 184.000 .000 & 3 \\
\hline 731.439 .428 & 509.942 .741 & 37.496.687 & 184.000 .000 & 4 \\
\hline 770.367.324 & 563.208.360 & 23.156 .965 & 184.000 .000 & 5 \\
\hline 790.215.222 & 593.182 .840 & 13.032.383 & 184.000 .000 & 6 \\
\hline 799.110 .452 & 608.465 .721 & 6.644 .731 & 184.000 .000 & 7 \\
\hline 802.293.017 & 615.315 .048 & 2.977 .968 & 184.000 .000 & 8 \\
\hline 802.831 .090 & 617.765 .623 & 1.065 .467 & 184.000 .000 & 9 \\
\hline 802.360.077 & 618.179 .939 & 180.138 & 184.000 .000 & 10 \\
\hline 801.659.572 & 617.817 .259 & 157.687- & 184.000 .000 & 11 \\
\hline
\end{tabular}

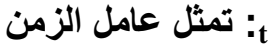

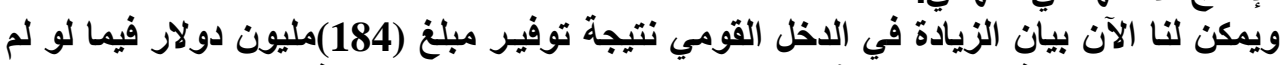
0

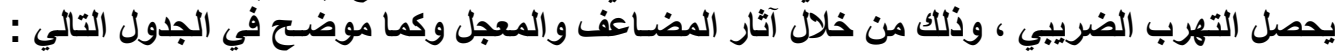

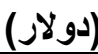

الآثار المترتبة على الوفرة النقدية من خلال تداخل المضاعف والمعجل

- إن قيمة كل عنصر في عمود الاستثمارات الأصلية تمثل الوفرة النقدية التي تم تقديرها عن مبالغ

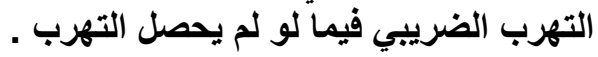


- إن قيمة كل عنصر في عمود الاستثمارات المولدة تمثل حصيلة: (قيمة عنصر الاستهلاك في الزمن t)

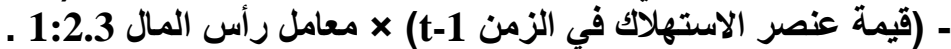
- إن قيمة كل عنصر في عمود الاستهلاك تمثل حصيلة : (الدخل القومي في الزمن t-1 ×

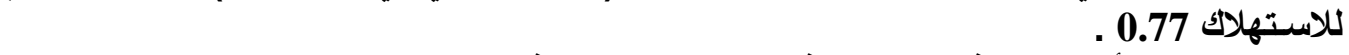

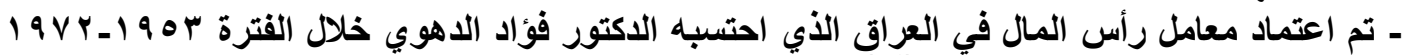

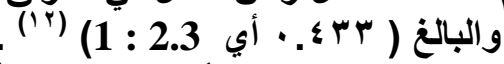

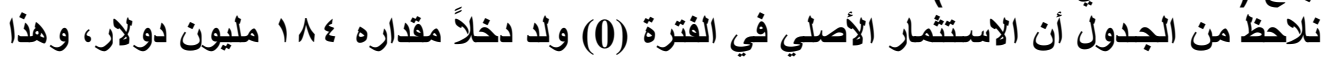

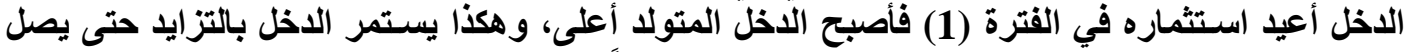

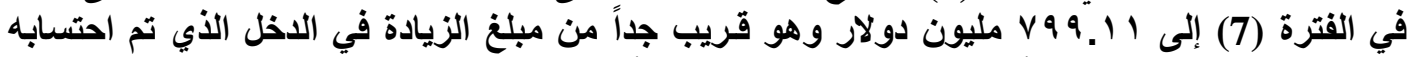

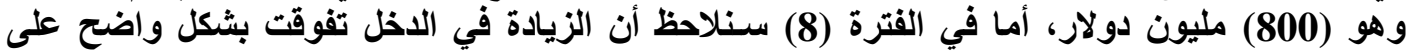
الزيادة المحتسبة بموجب نظرية المضاعف لتصبح (802.293) مليون دولار، ويفارق (2.293) مليون

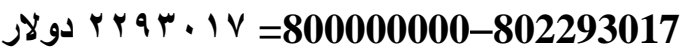
وتعود هذه الزيادة إلى فعل آثار الزيادة في الاستهلاك على خلق استثمارات جديدة دولار.

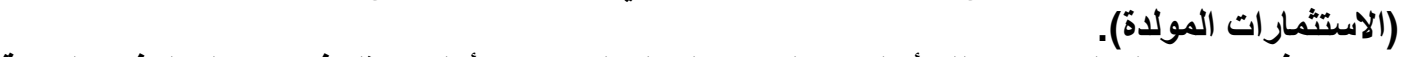

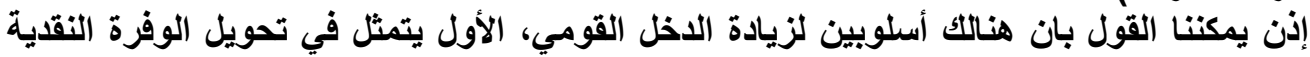

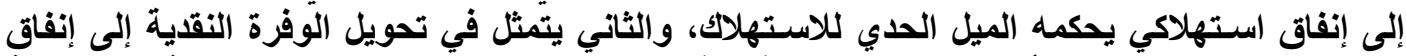

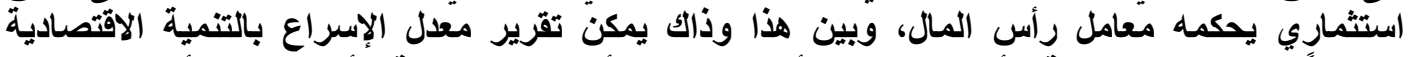

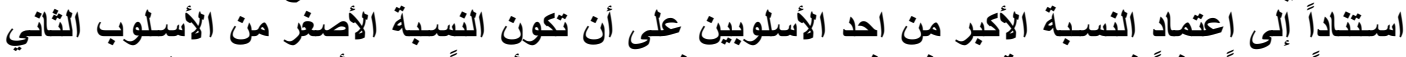

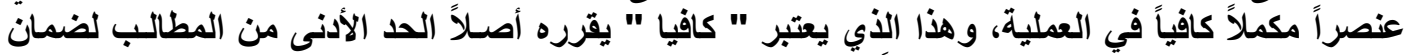

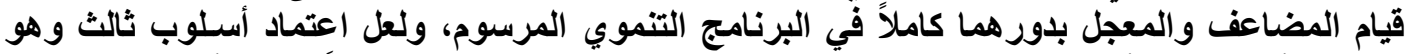

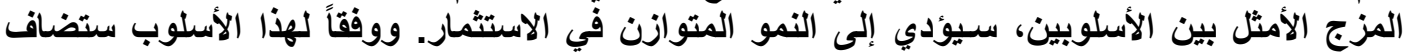

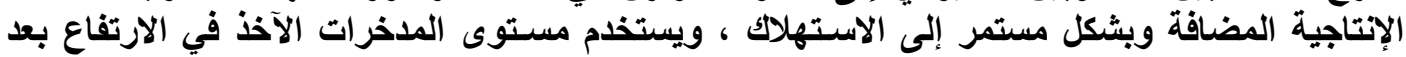

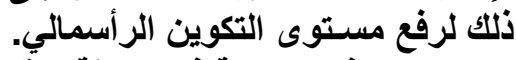

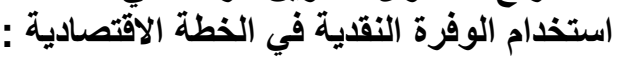

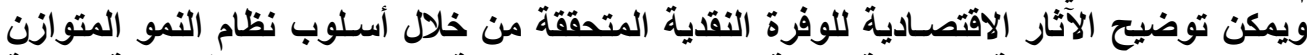

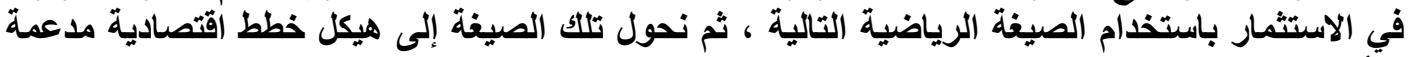

$$
\begin{gathered}
Y_{t}=Y_{t}+W Y_{t} / R=Y_{t}(1+W / R) \\
Y_{t+2}=Y_{t+1}+W Y_{t+1} / R=Y_{t+1}(1+W / R) \\
=Y_{t+1}(1+W / R)^{2} \\
\therefore Y_{t}=Y_{t}(1+W / R)
\end{gathered}
$$

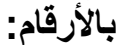

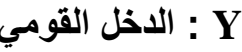

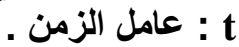

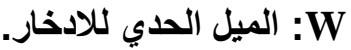

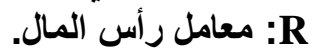

ويمكن توضيح آثار الوفرة النقاية السنوية والبالغة (2.293) مليون دولار من خلال تكنيك

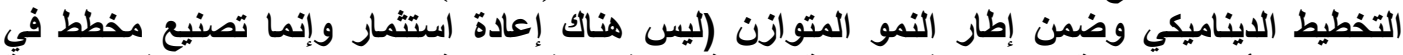

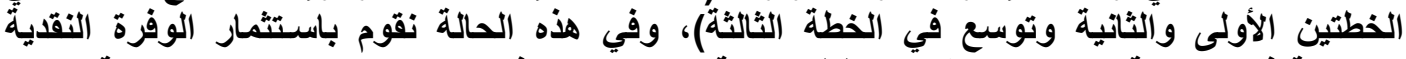

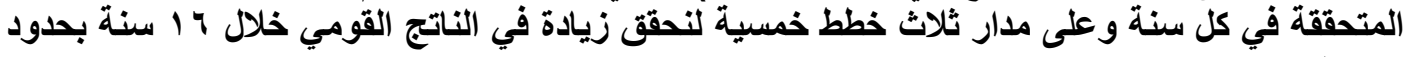

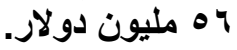




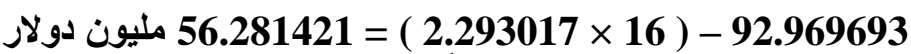

$$
\begin{aligned}
& \text { والجدول التالي يوضح ذلك تفصيلياً : }
\end{aligned}
$$

آثار الوفرة النقدية السنوية

\begin{tabular}{|c|c|c|c|c|c|c|}
\hline 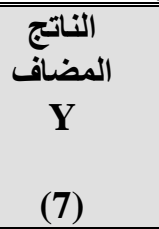 & $\begin{array}{c}\text { الاستثمار } \\
\text { I } \\
(6)\end{array}$ & $\begin{array}{c}\text { المدخرات } \\
\text { W }=0.23 \\
\text { (5) }\end{array}$ & $\begin{array}{c}\text { الاستهلاك (Y) } \\
0.77 \text { (Y) } \\
\text { (4) }\end{array}$ & المستثثرة النقاية & $\begin{array}{c}\text { الزمنتة } \\
\text { t } \\
\text { الفتزة } \\
(2)\end{array}$ & الخطة المبائية \\
\hline 0.229 & 0.527 & 0.527 & 1.766 & 2.293 & 0 & \multirow{6}{*}{ الخطة الأولى 2} \\
\hline 0.482 & 1.108 & 1.108 & 3.708 & 4.815 & 1 & \\
\hline 0.759 & 1.746 & 1.746 & 5.844 & 7.590 & 2 & \\
\hline 1.064 & 2.448 & 2.448 & 8.194 & 10.642 & 3 & \\
\hline 1.400 & 3.220 & 3.220 & 10.779 & 13.999 & 4 & \\
\hline 1.769 & 4.069 & 4.069 & 13.623 & 17.692 & 5 & \\
\hline 2.175 & 5.003 & 5.003 & 16.751 & 21.754 & 6 & \multirow{5}{*}{ الخطة الثانية } \\
\hline 2.622 & 6.031 & 6.031 & 20.197 & 26.223 & 7 & \\
\hline 3.114 & 7.162 & 7.162 & 23.976 & 31.138 & 8 & \\
\hline 3.654 & 8.405 & 8.405 & 28.139 & 36.545 & 9 & \\
\hline 4.249 & 9.773 & 9.773 & 32.719 & 42.492 & 10 & \\
\hline 4.903 & 11.278 & 11.278 & $\mathbf{3 7 . 7 5 7}$ & $\overline{49.035}$ & 11 & \multirow{5}{*}{ الخطة الثالثة } \\
\hline 5.623 & 12.933 & 12.933 & 43.298 & 56.231 & 12 & \\
\hline 6.415 & 14.754 & 14.754 & 49.393 & 64.147 & 13 & \\
\hline 7.285 & 16.757 & 16.757 & 56.098 & 72.855 & 14 & \\
\hline \multirow[t]{2}{*}{8.243} & 18.960 & 18.960 & 63.474 & 82.433 & 15 & \\
\hline & & & & 92.970 & & \\
\hline
\end{tabular}

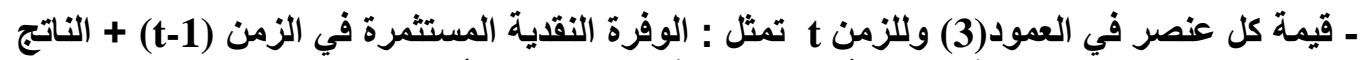

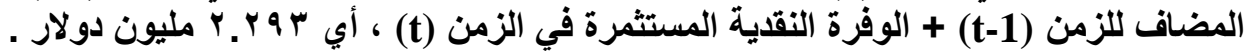

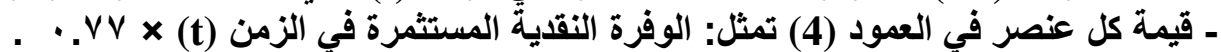

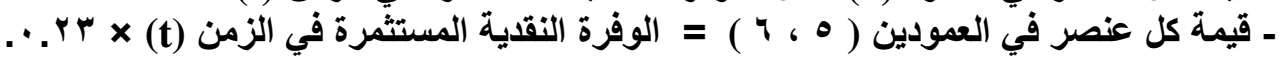

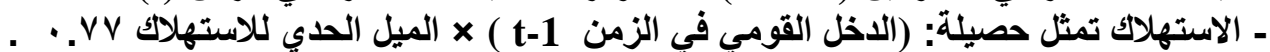

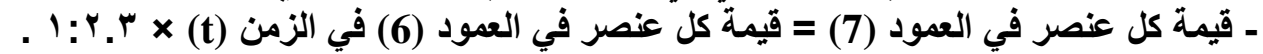


نخلص مما تقدم أن مبالغ التهرب الضريبي لو تم استثمارها فستؤدي إلى إنفاقات استهلاكية

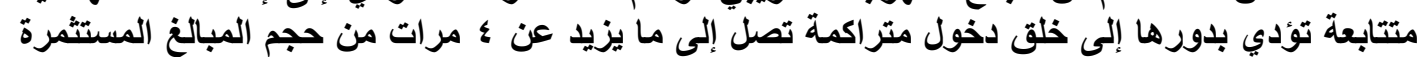

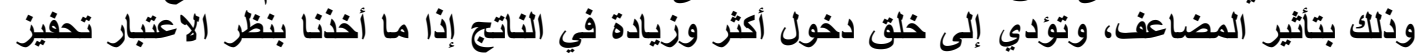

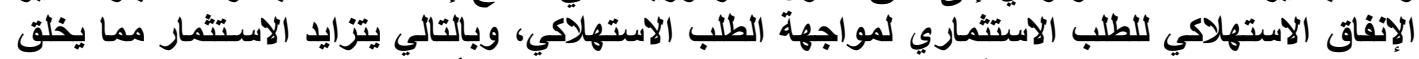

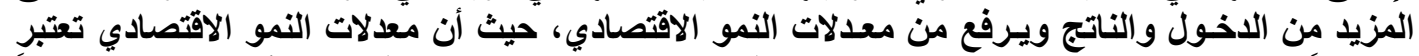

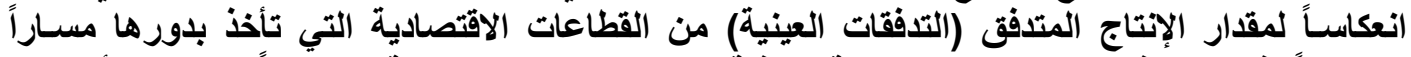

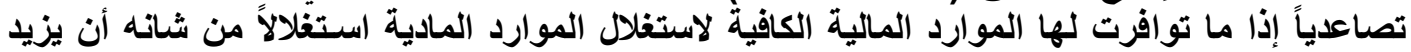

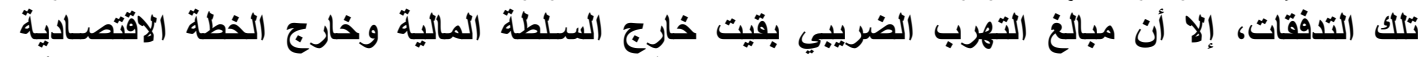

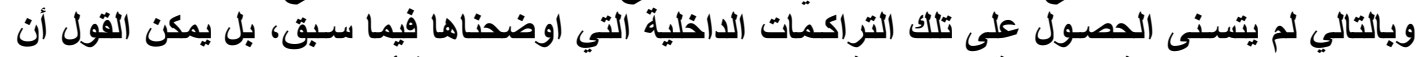

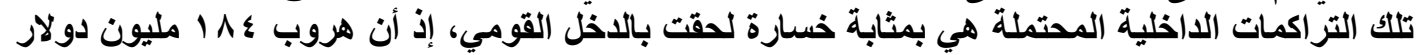

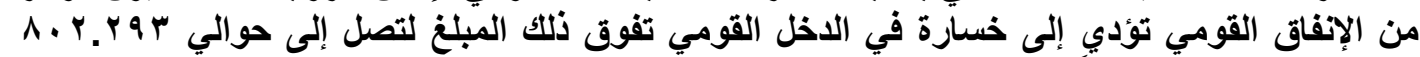

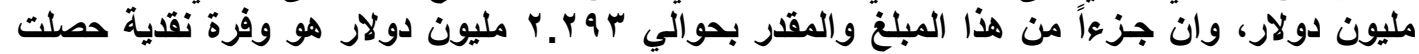

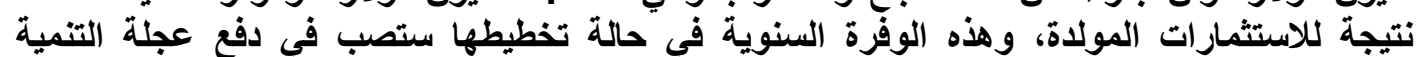

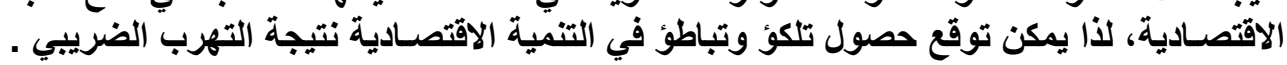


الاستنتتاجات

ا. لا يمكن أن ينشـأ الفسـاد الاقتصـادي من بيئات صالحة، فالبيئات الاقتصـادية والاجتماعية

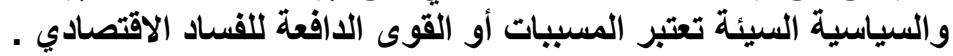

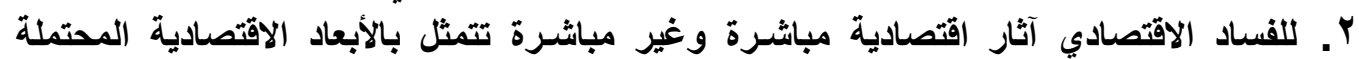
للفساد في مجالات اقتصادية متعددة. r. التلكؤ في تقديم القروض الخارجية والمنح جاء نتيجة انعدام إمكانية توفير شرط مكافحة الفساد

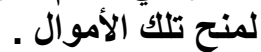
؛. . الآثار الاقتصادية السلبية للفساد تكون بثكل مركب فكل فسـاد يخلق فساداً مضاعفاً للأول ، فالأثر

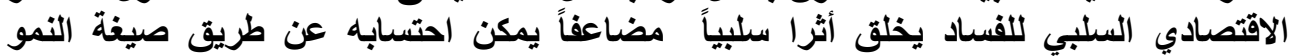

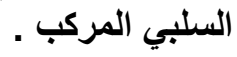

\section{التوصيات}

ا ا. الإصلاحات القضائية لضمان النزاهة والاستقلال وبناء القدرات.

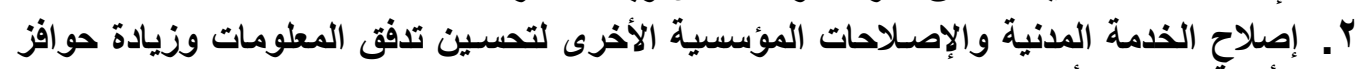

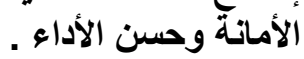

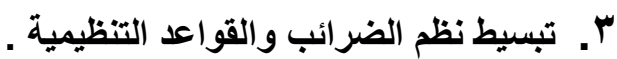
ع. استخدام المزادات، ومخططات العطاءات التنافسية، والآليات التنظيمية المستندة إلى السوق

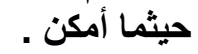

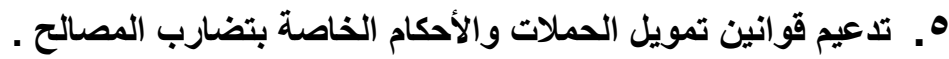

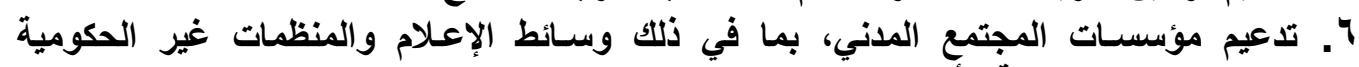

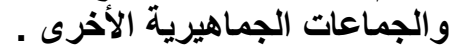

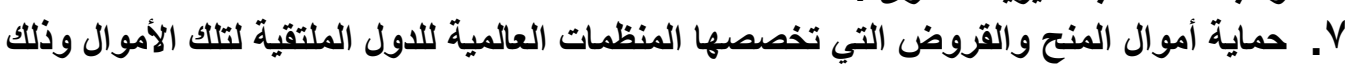

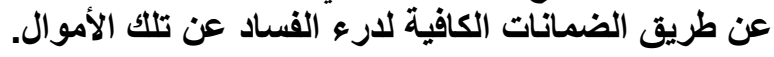
^. كسب الثركات المتعدية الجنسية إلى صفوف الجهود الإصلاحية من لفات خلال التركيز على تقليص

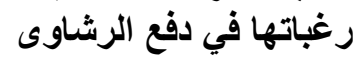

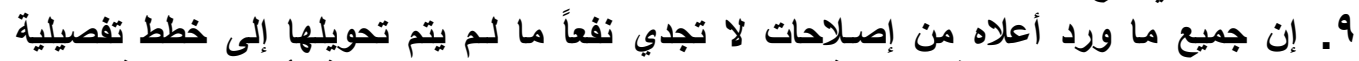

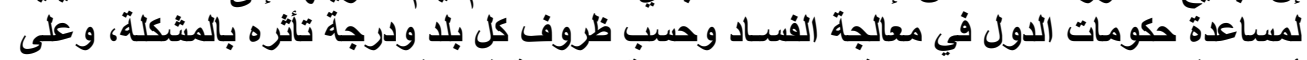
أساس ذلك تقدم المنظمات ألدولية مساعداتها الفية الفنية والمالية في هذا المجال . 
(1) Global Dynamic of Corruption ,The Role of the United Nations Helping Member State Build Integrity to Curb Corruption , U.N , CICP-3 ,Vienna , October $2002, \mathbf{P 2}$.

(ץ) روبرت كليتجارد، السيطرة على الفساد، ترجمة علي حسين حجاج، دار البثير للنشر والتوزيع،

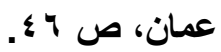

(") عبد الله الجابري د، الفسـاد الاقتصـادي- أنواعه، أسبابه، آثاره، علاجه، من بحوث المؤتمر الثالث

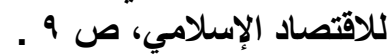

ورقة مناقثة للأستاذة سوزان- أكرمان بعنوان “،والفساد والحكم الرشيد” برنامج الأمم المتحدة

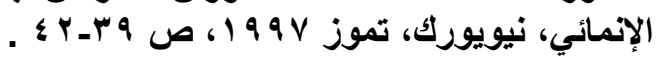

(0) الفسـاد والاقتصـاد العالمي، الفصل الثاني الذي كتبته سوزان روز- اكرمان تحت عنوان “،لاقتصاد

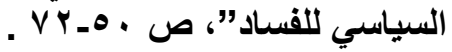

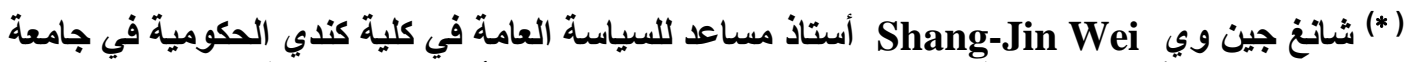

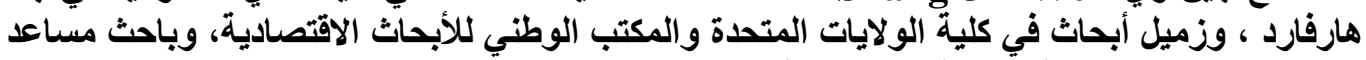

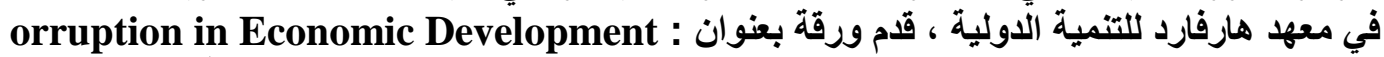

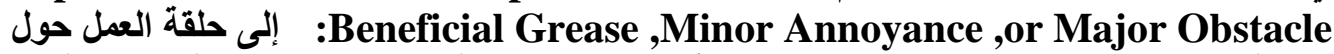

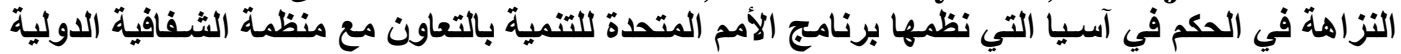

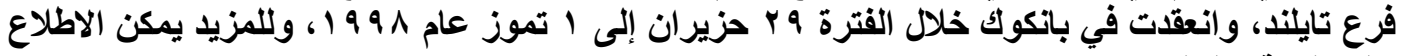
www.worldbank.org/wbi/governance/pdf/wei.pdf على الموقع التالي : (6) مقالة لغادة راضي بعنوان " الضر ائب الدولة تثتكي ...والممولين يتهربون " منشسورة على الموقع http://www.islamonline.net/iol-arabic/dowlia/namaa24-10-99/namaa.asp التالي :

http://ar.wikipedia.org

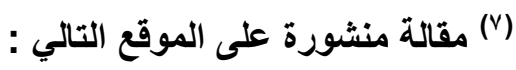

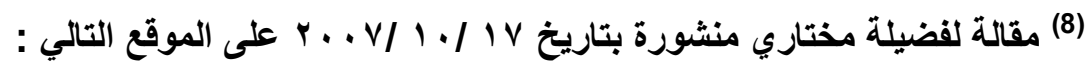

http://www.echoroukonline.com

(9) دـ ـ عبد العال الصكبان، "مقدمة في علم المالية العامة و المالية العامة في العراق "الطبعة الأولى،

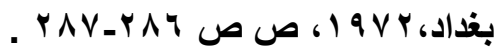

(·) المرحلتين الأولى والثانية أوردها دـ ـ عبد العال الصكبان في كتابه، انظر المصدر السابق، ص ص . $Y \wedge V-Y \wedge \neg$ 
(**) تم الاعتماد على نموذج رياضي في سياق بحث للادكتور يحيى غني النجار منثـور في مجلة كلية

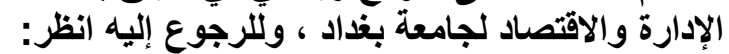

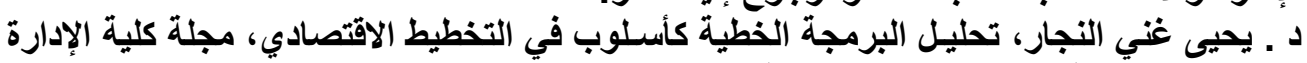

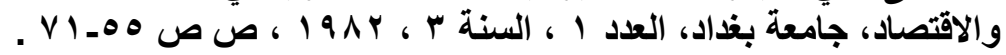

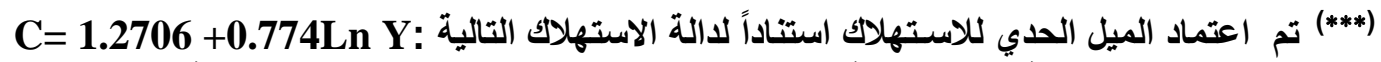

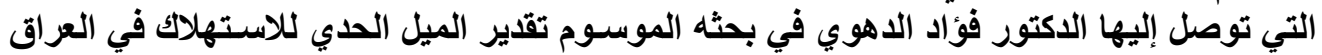

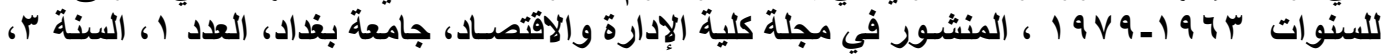

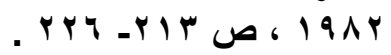

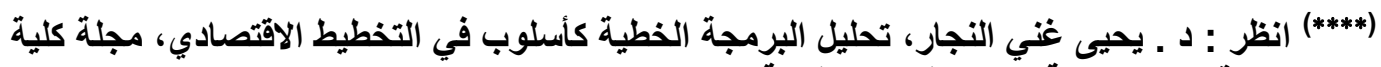

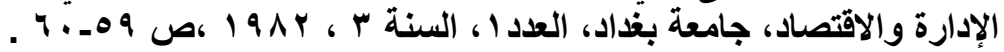

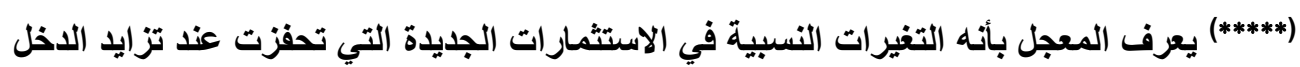

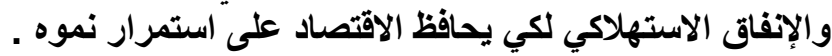

(') (انظر: د. يحيى غني النجار ، تحليل البرمجة الخطية كأسلوب في التخطيط الاقتصادي، مصدر سابق،

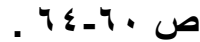

${ }^{(12)}$ Al-Dahwi , F .A. ,"Education and Economic Growth in Iraq ,1953-1972 “, Unpublished Ph .D. Thesis, The University of Newcastle upon Tyne, October, 1977,p.105 . 